\title{
On the occurrence of a less usual rainfall pattern in northeastern Brazil during the 2019 El Niño
}

Victor Azevedo Godoi ( $\nabla$ victorgodoirj@gmail.com )

OceanPact Geo Ltd https://orcid.org/0000-0001-7951-3017

Felipe M. de Andrade

University of Reading - Whiteknights Campus: University of Reading

\section{Research Article}

Keywords: Rainfall, northeastern Brazil, El Niño, anomalous heat sources, Madden-Julian Oscillation (MJO), linear baroclinic model

Posted Date: August 4th, 2021

DOl: https://doi.org/10.21203/rs.3.rs-227770/v1

License: (1) This work is licensed under a Creative Commons Attribution 4.0 International License. Read Full License 
On the occurrence of a less usual rainfall pattern in northeastern Brazil during the 2019 El Niño

3 Victor A. Godoi ${ }^{1 *}$, Felipe M. de Andrade ${ }^{2}$

$4{ }^{1}$ OceanPact Geo Ltd - R. Paulo Emídio Barbosa, s/n, Quadra 6a, Módulo 6 - Technology Park, Federal

5 University of Rio de Janeiro, Rio de Janeiro - RJ, 21941-615, Brazil.

$6{ }^{2}$ Department of Meteorology, Harry Pitt Building, University of Reading, Whiteknights Campus, Earley

7 Gate, PO Box 243, Reading RG6 6BB, UK.

8 *corresponding author: victorgodoirj@gmail.com; phone: +55 219 72321272; ORCID: 0000-0001-7951-

$9 \quad 3017$

10 Second author's ORCID: 0000-0001-6653-3916

\section{Abstract}

13 El Niño is generally associated with below-average rainfall in northeastern Brazil (NEB). In 2019, however, 14 the opposite rainfall pattern was observed during an EI Niño episode. Here, we explore the mechanisms 15 that overwhelmed typical El Niño-related conditions and resulted in above-average rainfall in NEB. We focus on the austral autumn, when El Niño is most related to rainfall anomalies in the region. The analysis of rainfall data from weather stations and the Global Precipitation Climatology Project, upper- and lowerlevel circulation reanalysis data, sea surface temperature data, outgoing longwave radiation data, and modelled data allowed us to identify that the autumn 2019 heavy rainfall in NEB was likely associated with three combined factors; these are: (1) the weak intensity of the 2019 El Niño; (2) local and remote diabatic heating anomalies, especially over the western South Pacific and tropical South Atlantic, which resulted in anticyclonic and cyclonic circulations in the upper and lower troposphere, respectively, over the tropical South Atlantic; and (3) sub-seasonal atmospheric convection anomalies over the western South Pacific, which reinforced the low-frequency convection signal over that region. This latter factor suggests the influence of the Madden-Julian Oscillation on rainfall in NEB during the first ten days of March. We discuss these mechanisms in detail and provide evidence for their associations with the anomalously heavy rainfall in NEB. Our results may assist in the planning of several crucial activities, such as water resources management and agriculture.

Keywords: Rainfall, northeastern Brazil, El Niño, anomalous heat sources, Madden-Julian Oscillation (MJO), linear baroclinic model.

\section{Declarations}

- Funding: No funding was received to assist with the preparation of this manuscript.

- Conflicts of interest/Competing interests: The authors declare no conflicts of interest.

- Availability of data and material: The data and material used in this research can be found at the following websites: 
www.inmet.gov.br,

https://apps.ecmwf.int/datasets/data/interim-full-moda/levtype=sfc/, https://psl.noaa.gov/data/gridded/data.noaa.ersst.v5.html, https://psl.noaa.gov/data/gridded/data.interp_OLR.html, https://psl.noaa.gov/data/gridded/data.gpcp.html, https://ccsr.aori.u-tokyo.ac.jp/ lbm/sub/lbm.html

- Code availability (software application or custom code): The codes used in this research are available under request to the first author. preparation, data analysis, and writing of this manuscript.

\section{Introduction}

Accurate rainfall predictions are of paramount importance to water resources management,

74 agriculture, livestock, energy generation (in those countries where hydropower has been adopted), and the 
safety of people and infrastructure. To predict rainfall accurately, knowledge of its local and remote drivers is essential.

Rainfall can be associated with phenomena varying in a wide range of timescales, from a cumulonimbus cloud, which can develop and dissipate in less than an hour (Wallace et al. 2006; Houze 2014), to persistent disturbances related to low-frequency climate oscillations, whose phases can last up to decades (e.g., Pacific Decadal Oscillation - Mantua and Hare 2002). A climate oscillation that has long attracted considerable attention from both the scientific community and industry is El Niño-Southern

82 Oscillation (ENSO - Walker and Bliss 1932, 1937; Bjerknes 1961, 1966; Wyrtki 1975; Neelin et al. 1998).

83 ENSO is an interannual oscillation (2-7 years - Trenberth and Hurrell 1994; Cane 2005; McPhaden et al. 2006) composed of two active phases, EI Niño and La Niña, whose main signatures are observed through sea surface temperature (SST) variations in the central and eastern equatorial Pacific waters (Chase et al. 2006). El Niño is associated with anomalously warm waters, and La Niña with anomalously cold waters.

ENSO has been related to rainfall anomalies all over the globe (Lin and Qian 2019). For example, southeastern Australia can experience severe droughts during El Niños (Nicholls 1985, 1991; Cai and Cowan 2008; Taschetto and England 2009; Cai et al. 2011; Davey et al. 2014), while heavy rainfall generally occurs in Peru and southern Brazil (Davey et al. 2014; Cai et al. 2020). ENSO-related SST variations in the central and eastern Pacific influence weather in remote locations through teleconnection mechanisms. Moisture, momentum, and heat transports from a tropical area to another are carried out by the Walker circulation (tropic-tropic teleconnection), and from a tropical to a subtropical area by the Hadley circulation (Grimm and Ambrizzi 2009; Stan et al. 2017). Variations in the Hadley cell, resulting from tropical diabatic (convective) heating anomalies, disturb subtropical Rossby wave sources (Shimizu and Cavalcanti 2011), which, in turn, induce barotropic Rossby waves that change the flow at mid and high latitudes (L'Heureux and Thompson 2006) (tropical-extratropical teleconnection).

Northeastern Brazil (NEB) is one of the regions impacted by ENSO fluctuations (Grimm 2011; Tedeschi et al. 2015, 2016), with severe droughts generally occurring during El Niños (Rodrigues et al. 2011), and heavy rainfall during La Niñas (Rodrigues and McPhaden 2014). The strength of rainfall anomalies in NEB may change according to the ENSO flavour and year's season. Moderate rainfall anomalies are associated with central Pacific (Modoki) El Niño events, whereas stronger anomalies relate to eastern Pacific (canonical) El Niño events (Rodrigues et al. 2011). On the other hand, rainfall anomalies in NEB are generally strong during both central and eastern Pacific La Niña events (Tedeschi et al. 2016). Rainfall extremes are most pronounced in the austral autumn (Grimm 2011), when rainfall anomalies can have opposite signals during the different ENSO flavours - below-average rainfall is usually expected during canonical EI Niños, while above-average rainfall can occasionally occur during El Niño Modoki (Tedeschi et al. 2016). Despite these relationships between ENSO events and rainfall in NEB being relatively well established, no two El Niño/La Niña episodes have exactly the same characteristics (Cai et al. 2020). The mechanisms responsible for different rainfall conditions between events need to be well understood, especially those that result in anomalies whose sign is contrary to that expected for a given 
112 ENSO phase (as in Grimm et al. 2020). Sectors requiring rainfall information to plan their activities will 113 benefit greatly from this knowledge.

114 Although rainfall anomalies in NEB are generally negative (below-average rainfall) during El Niño 115 episodes, the opposite rainfall pattern was observed in the austral autumn [March-April-May (MAM) 116 herein, we use the acronym "MAM" to refer to austral autumn in a general sense, not necessarily from 117 beginning to end of the season] during the 2019 El Niño - this rainfall behaviour is shown and discussed in 118 detail in Section 4. Seasonal forecasts issued in February 2019 already indicated a 35-40\% chance of 119 unusually wet conditions in NEB for MAM (Nobre et al. 2019). Such unusual 2019 wet conditions have not 120 yet been explored. Here, we investigated the dynamical processes related to this atypical rainfall behaviour 121 in NEB during the 2019 El Niño by analysing several datasets. Firstly, we examined upper- and lower-level 122 circulation reanalysis data, SST data, and gridded rainfall data to understand the atmospheric and oceanic 123 conditions that prevailed during the period of analysis and those that are generally observed during El Niño 124 episodes. Secondly, we used weather station rainfall data to analyse the most intense rainfall anomalies in 125 NEB in MAM 2019. Thirdly, the regions where anomalous heat sources (diabatic heating anomalies) could 126 have brought about the circulation anomalies that resulted in rainfall in NEB were inferred from rainfall data 127 and by applying the influence functions (IFs) approach to the results of a dry linear baroclinic model (LBM). 128 The same model was then run to investigate how these diabatic heating anomalies could potentially have 129 modulated above-normal rainfall in NEB in March 2019. The simulations focussed on March 2019 because 130 this was the month when rainfall anomalies were most extreme and the Madden-Julian Oscillation (MJO 131 Madden and Julian 1971, 1972, 1994) phase was favourable to rainfall in NEB (shown later). Recent work 132 has demonstrated that the MJO is associated with rainfall in NEB (e.g., Grimm 2019; Giovannettone et al. 133 2020). The MJO is the dominant mode of sub-seasonal variability in the tropical atmosphere (Mo and 134 Nogues-Paegle 2005), and can modulate ENSO-related impacts over South America (Shimizu and 135 Ambrizzi 2016; Shimizu et al. 2017). Since rainfall conditions in NEB during the 2019 austral autumn 136 differed from those expected during El Niño episodes, we also looked into how MJO activity could have 137 contributed to circulation anomalies associated with these conditions. This was carried out by using the 138 daily Real-time Multivariate MJO (RMM) index (Wheeler and Hendon 2004) and filtered outgoing longwave radiation (OLR - as a proxy for tropical deep atmospheric convection) fields.

The datasets and model simulations mentioned in the previous paragraph are described in the next 142 behaviours of SST, rainfall, and upper- and lower-level circulations in MAM during El Niño events. Our 143 results are presented and discussed in Sections 4-6. Lastly, our key findings are reported in Section 7. 
Assessments of the upper- and lower-level atmospheric circulations, SST, and rainfall were made through $200-\mathrm{hPa}$ and $850-\mathrm{hPa}$ zonally asymmetric streamfunction (ZASTRF), SST, and rainfall fields, respectively. ZASTRF data were calculated from $200-\mathrm{hPa}$ and $850-\mathrm{hPa}$ zonal and meridional wind data sourced from the European Centre for Medium-Range Weather Forecasts (ECMWF) ERA-Interim reanalysis (Dee et al. 2011) at the spatial resolution of $1.5^{\circ} \times 1.5^{\circ}$. SST data were obtained from the National Oceanic and Atmospheric Administration (NOAA) Extended Reconstructed SST version 5 (ERSSTv5) at the $2.0^{\circ} \times 2.0^{\circ}$ spatial resolution (Huang et al. 2017). Gridded rainfall data were sourced from the NOAA Global Precipitation Climatology Project (GPCP) at the spatial resolution of $2.5^{\circ} \times 2.5^{\circ}$ (Adler et al. 2018). All data described in this paragraph are monthly and span March-May seasons between 1979 and 2019. Daily OLR data were also obtained to examine potential relationships between MJO convective activity and atmospheric circulation anomalies associated with the above-normal rainfall in NEB. OLR data were derived from the NOAA Interpolated OLR at the spatial resolution of $2.5^{\circ} \times 2.5^{\circ}$ (Liebmann and Smith 1996). The spatial resolutions of ZASTRF and SST data were reduced to $2.5^{\circ} \times 2.5^{\circ}$, using linear interpolation, to facilitate the comparison to the results generated here and to obtain a uniform resolution among the ZASTRF, SST, rainfall, and OLR data. ZASTRF, SST, rainfall, and OLR anomalies were calculated using the 1979-2019 long-term mean.

Monthly accumulated rainfall data, measured at seven weather stations near the northern coast of NEB (Fig. 1), were sourced from the Brazilian National Institute of Meteorology (INMET). The selection of stations was based on location and data availability. We focussed on stations near the coastline sector between northwestern Maranhão (MA) and northeastern Rio Grande do Norte (RN) whose data span the period March 1979-May 2019. As we show later, this coastline sector experienced the highest rainfall amounts in NEB in MAM 2019. To determine the strength of rainfall anomalies in MAM 2019 and the months within that season, seasonal and monthly anomalies were normalised by the standard deviation. Calculations considered the period 1979-2019 as the climatological reference. Seasonal anomalies were computed only for years whose March, April, and May data were available. Extreme positive [negative] anomalies were defined as those values higher [lower] than one standard deviation about the mean.

To provide an overview of the SST, rainfall, and upper- and lower-level circulations typical behaviours in MAM during El Niño events, we calculated least-squares linear regressions of SST, rainfall, and ZASTRF seasonal anomalies onto ENSO indices. Niño 3, Niño 4, and Niño 3.4 indices were calculated by averaging SST anomalies over their respective regions (Trenberth 1997; Trenberth and Stepaniak 2001). The indices were, then, normalised by their respective standard deviations. The calculation of the El Niño Modoki Index (EMI; Ashok et al. 2007) followed standard procedures. Regression calculations considered the period 1979-2019. SST, rainfall, and ZASTRF fields were scaled by one standard deviation anomaly of the ENSO indices, following Lo and Hendon (2000). Statistical significance of regressed values was evaluated using a two-tailed Student's $t$-test (Allen 1997) and a confidence level equal to $90 \%$ ( $p$-value equal to 0.1 ). This test considered the effective number of spatial degrees of freedom described in Livezey 
and Chen (1983). As the regressed fields onto Niño 3, Niño 4, and Niño 3.4 indices are roughly similar (not shown), we only show and discuss regression results for Niño 3.4 and EMI.

We conducted two sets of numerical simulations to achieve two different goals: (1) to identify the diabatic heating anomalies that most disturbed the circulation at a few target locations. To accomplish that, we used a dry LBM - i.e., with no moisture effects - and the IFs approach. IFs have been generally applied to the results of barotropic vorticity equation models to assess the impacts of vorticity and divergence sources on atmospheric circulation, and are an invaluable tool to diagnose the origin of tropical-extratropical teleconnections (e.g., Branstator 1985; Grimm and Silva Dias 1995; Grimm 2003; Grimm and Reason 2011, 2015; Grimm 2019); and (2) to confirm the origin of the atmospheric circulation anomalies that most contributed to the occurrence of above-normal rainfall in NEB in March 2019. The dry LBM used to achieve goal number (1) was also employed to achieve goal number (2).

We chose the dry LBM described in Watanabe and Kimoto (2000) to carry out the simulations, and this was because this model easily allows for the separation of anomalous atmospheric responses from the basic state (Tseng et al. 2019). LBMs include the effect of mean zonal wind vertical shear, which plays a crucial role in the meridional propagation of planetary-scale circulation anomalies triggered by tropical heat sources (Kasahara and Silva Dias 1986; Majda and Biello 2003).

The simulations used thermal forcings (TFs) in the model's temperature tendency equation, and the March climatology (1979-2019) to integrate the primitive equations. The climatological basic state was composed of temperature and wind fields at 23 pressure levels (allocated between $1000 \mathrm{hPa}$ and $1 \mathrm{hPa}$ ) and surface pressure, all extracted from the ECMWF ERA-Interim reanalysis. These data were interpolated, at 20 sigma levels (L20), to the coarsest model resolution (i.e., $5.625^{\circ}$ - triangular spectral truncation at zonal wavenumber 21 - T21) to reduce computational costs. Sensitivity tests considering the finer spatial resolution T42 were also carried out. Although T42 resolution is generally adequate for representing most quantities of interest in climate diagnostics (Trenberth and Solomon 1993), results did not improve significantly (not shown). To enhance stability and inhibit the development of small-scale eddies, Rayleigh friction and Newtonian cooling were considered in the simulations using an e-folding timescale of 20 days in all vertical layers, except at the topmost sigma level and the lowest three levels, where the damping timescale was defined as 0.5 days, following Tseng et al. (2020). A sixth-order biharmonic horizontal diffusion $\left(\nabla^{6}\right)$, with damping timescale of 20 hours for the shortest wavelength (Jin and Hoskins 1995; Ambrizzi and Hoskins 1997), was also employed.

The model was integrated for 30 days, considering a 40-minute timestep and a steady TF. The quasi-stationary circulation response to anomalous diabatic heating occurred around the fifteenth day of the simulations (before baroclinic instability dominated the flow), which corroborates the results of previous work (e.g., Jin and Hoskins 1995; Seo and Son 2012). Thus, our discussions on the modelled results concern day 15 of the simulations. Modelled $200-\mathrm{hPa}$ and $850-\mathrm{hPa}$ streamfunction fields had their zonal mean removed, hence becoming ZASTRF fields, to make teleconnection responses more notable (e.g., Jin and Hoskins 1995; Grimm and Reason 2011, 2015). 
In the first set of simulations, the model was forced with vertical profiles having a peak heating rate of $5 \mathrm{~K} /$ day at $\sim 0.4$ (sigma level $-\sigma$ ), as in Jin and Hoskins (1995). Such vertical heating profiles have been identified as the tropical diabatic heating variability dominant mode (Zhang and Hagos 2009), being, therefore, well suitable to represent the effects of condensation heating associated with deep convection (Schumacher et al. 2004, 2007).

The quasi-stationary model was represented as follows:

$$
M L=T F
$$

where $M$ is the modelled variable, $T F$ is the thermal forcing, and $L$ is the linear operator, determined by the basic state and energy dissipation.

The IFs, applied to the first set of modelled results, were calculated following Liu et al. (1998):

$\varphi_{0}, h(\sigma)$ is the heating source vertical profile at $\left(\lambda_{0}, \varphi_{0}\right)$, and $G\left(\lambda, \varphi, \sigma, \lambda_{0}, \varphi_{0}\right)$ is the IF of (1), or the model response at a target point (TP) of longitude $\lambda$ and latitude $\varphi$. Thus, by calculating $G\left(\lambda, \varphi, \sigma, \lambda_{0}, \varphi_{0}\right)$, one can identify which TF affects the area around a given TP the most. The highest [lowest] IF values indicate where heating anomalies are most capable of modulating positive [negative] ZASTRF anomalies around the TP. Because the model is linear, the opposite interpretation is valid for cooling anomalies; i.e., the highest [lowest] IF values indicate where cooling anomalies are most capable of modulating negative [positive] ZASTRF anomalies around the TP. IFs were calculated for the results of 896 (14 latitude points $\times 64$ longitude points) quasi-stationary simulations, considering TFs at grid points located between $35^{\circ} \mathrm{S}$ and $35^{\circ} \mathrm{N}$. Although TFs associated with extratropical SST anomalies may also affect the atmospheric circulation (e.g., Zhou 2019), we focussed on tropical and subtropical TFs related to condensation heating (and upper-level divergence anomalies) because they are nearly independent of the rotational flow (Grimm and Silva Dias 1995). Furthermore, tropical and subtropical TFs are the primary extratropical Rossby wave sources (Teng and Branstator 2019).

The IFs approach results and GPCP rainfall data assisted in locating the tropical and subtropical regions where heating and cooling anomalies likely most influenced above-normal rainfall in NEB in March 2019. To confirm the impacts of these heating and cooling anomalies on the atmospheric circulation anomalies associated with the rainfall in NEB, we carried out the second set of simulations and compared their results to ZASTRF reanalysis data. Diabatic heating anomalies vertical profiles were estimated using ERA-Interim three-dimensional temperature and wind data. The apparent heat source $\left(Q_{1}\right)$ was estimated 
comprises different physical processes, such as condensation heating, evaporation, radiative cooling, and eddy heat flux convergence (Yanai et al. 1973), condensation heating dominates in regions of deep convective activity. The calculation of $Q_{1}$ anomalies for March 2019 considered the period 1979-2019 as the climatological reference.

Lastly, as we show in Section 4, accumulated rainfall varied considerably from month to month in MAM 2019, suggesting that sub-seasonal atmospheric variability might have contributed to modulating rainfall anomalies. To point out potential links between the MJO and rainfall anomalies in NEB, we used the RMM index. A more thorough exam of such links was carried out by filtering daily OLR anomalies for March 2019 at low frequency (>90 days) and the sub-seasonal band (30-90 days) using a Lanczos filter (Duchon 1979) - we focussed on March 2019 because that is when MJO phases seem to have favoured rainfall intensification in the study area the most (shown later). Filtered OLR anomalies were monthly averaged for each frequency band, and the resulting averages were compared between themselves and to the unfiltered monthly anomaly for March 2019.

\section{Overview of El Niño-related conditions in the austral autumn}

To facilitate our discussions, we describe very briefly, in this section, SST, rainfall, and upper- and lower-level circulation conditions associated with EI Niño events in the austral autumn. The description is based on linear regressions of SST, rainfall, and ZASTRF onto two ENSO indices, the Niño 3.4 and EMI.

Temporary changes to tropical SST typical patterns, like those that happen during El Niño events, generally induce variations in both intensity and location of tropical atmospheric convection. These variations, in turn, generate atmospheric circulation anomalies that influence weather and climate all over the globe (Trenberth and Caron 2000). SST anomalies in the tropical Pacific strongly influence rainfall conditions in NEB. Fig. 2 shows that anomalous warming (positive SST anomalies) in the central and eastern tropical Pacific (Niño 3.4 region $-5^{\circ} \mathrm{S}-5^{\circ} \mathrm{N}, 170^{\circ}-120^{\circ} \mathrm{W}$ ) usually results in increased rainfall in those regions, and reduced rainfall in NEB. Also related to this anomalous warming are the upper-level cyclonic and lower-level anticyclonic circulations over NEB (positive and negative ZASTRF anomalies, respectively), which are associated with decreases in rainfall in NEB and, on some occasions, severe droughts (Cai et al. 2020) - the opposite circulation pattern appears over the central and eastern tropical Pacific. On the other hand, Fig. 3 shows that warmer SST centred at about $0^{\circ} \times 180^{\circ}$, associated with El Niño Modoki events, generally induces increased rainfall right over it and to the west of it, and reduced rainfall along the tropical Pacific, from about $170^{\circ} \mathrm{W}$ all the way to South America. Reduced rainfall is also observed over most parts of NEB, although with no statistical significance (other studies, e.g., Cai et al. (2020), have found statistically significant results when relating EI Niño Modoki events to rainfall in NEB, which may result from the period of analysis and technique employed by the authors). Upper- and lowerlevel circulation patterns are similar to those shown in Fig. 2, but less intense and shifted westward. The lower-troposphere circulation over NEB, however, is not statistically significant in Fig. 3. Therefore, 
circulation patterns related to both canonical and Modoki events induce decreases in rainfall in NEB, which are more remarkable close to the northern coast, as also shown in Cai et al. (2020). Despite that, the intensity and statistical significance of El Niño Modoki-related atmospheric conditions over NEB indicate that rainfall anomalies are more likely to deviate from the expected behaviour than those related to canonical El Niños (also shown in Tedeschi et al. 2016).

\section{Oceanic and atmospheric conditions in the 2019 austral autumn}

\subsection{SST and rainfall anomalies}

In MAM 2019 and the months within that season, El Niño-related warmest waters occurred in the central Pacific, centred at around $165^{\circ} \mathrm{W}$ (see SST fields in Fig. 4). Heavier rainfall was also observed in the central Pacific (Fig. 4), with the highest amounts taking place further to the west, at around the International Date Line $\left(180^{\circ}\right)$. In March 2019, heavier rainfall and warmer SST occurred in the tropical South Atlantic and near the southeastern coast of Australia, in the Tasman Sea, whereas the tropical western South Pacific experienced lighter (below-normal) rainfall (the importance of these regions to our study is evidenced later).

Heavier-than-usual rainfall has been found to take place in NEB when waters in the Niño 3.4 region are warmer than $0.5^{\circ} \mathrm{C}$ and deep convection is absent over these waters, as occurred at the initial stages of the 2018-2019 El Niño - this rainfall pattern is, nevertheless, statistically non-significant (Hu et al. 2020). If deep convection is present over the Niño 3.4 region warmer waters instead, rainfall in NEB is significantly lighter than usual (Hu et al. 2020 - we note that this comment and the previous one are based on composites of monthly mean precipitation anomalies for the period January 1979-December 2019). Despite SST and rainfall conditions in the Niño 3.4 region in MAM 2019 resembling this second case more (deep convection failed to exist everywhere over the Niño 3.4 region, though - not shown), rainfall was anomalously heavy in most parts of NEB (Fig. 4).

Rainfall fields show that the highest rainfall amounts in NEB in MAM 2019 occurred in the region's northern portion (Fig. 4). Because of that, we expand our discussion considering weather station rainfall data measured at seven sites near the NEB northern coastline sector (Fig. 1). Furthermore, to understand the relative strength of the rainfall anomalies observed in MAM 2019, we compare them to those observed during three extreme EI Niños. These extreme events supposedly reveal the relationship between El Niños and their associated rainfall anomalies in NEB more clearly than non-extreme events and, therefore, provide the reader with a better understanding of such a relationship.

The usual rainfall behaviour in NEB during El Niño events can be clearly noted in some time series of Fig. 5 in years of extreme EI Niños, such as 1983, 1998, and 2016 (vertical dotted lines). Drought (i.e., normalised anomaly values lower than -1 standard deviation) for the following stations reflects the $1983 \mathrm{El}$ Niño intensity: Turiaçu and São Luís (March, April, and May), Piripiri (April), Sobral (March and April), and Fortaleza (April and May). These outstandingly small rainfall amounts can also be noted for all stations in 
MAM 1983, except for Apodi and Ceará-Mirim. In 1998, drought in NEB was less severe than in 1983, in general. In other words, normalised anomaly values for 1998 were higher than those observed in 1983 at most stations and in most periods (months and season) analysed. The easternmost stations (Apodi and Ceará-Mirim) are exceptions. At Apodi station, negative rainfall anomalies were more pronounced in April, May, and MAM 1998 than in the same period in 1983; although in MAM, normalised anomalies were extreme in neither 1983 nor 1998. Rainfall at Ceará-Mirim station behaved similarly, with negative normalised anomalies more pronounced in March, April, and MAM 1998. In this case, however, anomalies were not extreme in April of both years. A multi-year drought in NEB started in 2011 (Grimm 2018), and was aggravated by the 2016 El Niño-related effects. Such drought affected over 30 million people and resulted in more than US $\$ 25$ billion in economic losses (Cai et al. 2020). The weather stations' data selected here show that the 2016 extreme El Niño was the least associated with drought in the northernmost portion of NEB, compared to both 1983 and 1998 events. Normalised anomalies for 2016 were extremely negative only at Turiaçu (May), Piripiri (April), and Apodi (April and MAM). The 2016 extreme values were lower than those of 1983 (April and MAM) and 1998 (MAM) only at Apodi station, which may be associated, for instance, with local effects, or even the Atlantic Multidecadal Oscillation phase change around 1998 (Kayano and Capistrano 2014; Levine et al. 2017). A remarkable difference among these three El Niño events is their signature in the Pacific Ocean. Above-average SST featured most prominently in eastern equatorial Pacific waters during the 1983 and 1998 events, and in the western and central Pacific during the 2016 El Niño (L'Heureux et al. 2017).

The 2018-2019 El Niño was only weak (weaker east-west SST anomaly gradient across the tropical Pacific than usual El Niños - Hu et al. (2020)) and characterised by a delayed ocean-atmosphere coupling (Johnson et al. 2019) - i.e., tropical deep atmospheric convection did not shift eastward at the El Niño initial stages despite conducive oceanic conditions. An anomalous SST gradient between the western and central equatorial Pacific delayed the formation of deep atmospheric convection over the central tropical Pacific and, consequently, of its associated teleconnection patterns (Johnson et al. 2019). Even though such initial decoupling only lasted from October to December 2018 (Hu et al. 2020), NEB experienced positive rainfall anomalies in MAM 2019 (Figs. 4 and 5), which contrasts the dry conditions typically observed in the region during EI Niño episodes (Figs. 2 and 3). Positive rainfall anomalies were observed at all seven stations in March 2019, with extreme values occurring at four of them (Turiaçu, São Luís, Piripiri, and Ceará-Mirim). In April 2019, extreme rainfall took place at three out of the seven stations analysed (Turiaçu, Piripiri, and Ceará-Mirim). Fortaleza was the only station that experienced extreme rainfall in May 2019. In MAM 2019, positive anomalies were remarkably strong at three stations (Turiaçu,

364 Piripiri, and Ceará-Mirim). Values were quite close to one standard deviation at all stations whose anomalies were not extreme in that season, excepting at Apodi station, where the normalised anomaly value was close to zero. It is worth noting that the three stations that experienced unusually heavy rainfall in MAM 2019 are not close together. In fact, two of these stations are the westernmost and easternmost 
stations, whereas the third one is nearly in the middle of them. There were no extremely negative anomalies (below-normal rainfall) in the 2019 period analysed.

In 2019, São Luís, Ceará-Mirim, and Piripiri stations recorded not only high accumulated rainfall values but some of the highest values of the last 40 years (Fig. 5). At São Luís station, rainfall in March 2019 was the heaviest on record (1979-2019) for March months, with the normalised anomaly value $\sim 2.3$ times higher than the standard deviation. Also in March 2019, Ceará-Mirim station experienced the thirdheaviest March rainfall since 1979 ( 1.5 heavier than the standard deviation). Moreover, rainfall amounts at Ceará-Mirim station in April and MAM 2019 were the second-heaviest relative to corresponding periods in previous years ( 1.9 heavier than the standard deviation in both cases). In 2019, Piripiri station recorded the second- and third-heaviest rainfall amounts for April and MAM, respectively, when considering the period 1979-2019 ( 1.6 and $\sim 1.3$ heavier than the standard deviations for April and MAM, respectively).

The previous three paragraphs highlight the month-to-month rainfall amount differences for data recorded at individual weather stations during an EI Niño event. These results for the austral autumn extend those found by Grimm (2003) for the extended austral summer (November-February). The aforementioned month-to-month differences suggest a contribution of sub-seasonal oscillations (e.g., the MJO) to rainfall variability in NEB, which can disturb EI Niño-related impacts (addressed later in Section 6).

\subsection{Atmospheric circulation anomalies}

The ocean-atmosphere coupling during MAM 2019 triggered circulation conditions over NEB (Fig. 6) that differ from those expected during El Niño events (Figs 2 and 3). An upper-level (200 hPa) Rossby wave train connected the South Pacific to the tropical South Atlantic through the extratropics (more notable in MAM and March 2019), resulting in an anticyclonic circulation over the tropical South Atlantic and part of eastern South America (Fig. 6). This anticyclonic circulation likely caused upper-level divergence over NEB, favouring rainfall occurrence in the region, unlike the typically-observed dry conditions associated with El Niño-related cyclonic circulations (Figs 2 and 3). In the lower troposphere (850 hPa), the circulation also opposed the EI Niño-related usual conditions, with a cyclonic circulation appearing over part of NEB, except in May 2019 (Fig. 6).

\section{Model results}

5.1 Influence functions The impacts of diabatic heating anomalies on circulation were assessed at five TPs (Fig. 7 - the TPs can also be seen in the March panels of Fig. 6). The selection of TPs 1-4 aimed to understand the origin of the teleconnection pattern that connected the extratropical South Pacific to the tropical South Atlantic. TP5 was selected to identify potential TFs influencing the local circulation.

The IFs results for TPs 1-4 (Fig. 7) indicate that circulation anomalies associated with the 
over the western South Pacific - this is shown by the sign reversal of IF results as TP locations vary (Fig. 7). Although TFs over other regions (e.g., central South Pacific) may seem to influence circulation around TPs strongly, the signs of IFs results do not reverse as TP locations change. The absence of such a sign reversal results in conflicting influences at the TPs, as highlighted by Grimm and Silva Dias (1995). The IFs results for TPs 1 and 2 show that the dipole-like rainfall pattern observed in the GPCP data, with negative anomalies (cooling) at $\sim 12^{\circ} \mathrm{S} / 160^{\circ} \mathrm{E}$ and positive anomalies (heating) at $\sim 35^{\circ} \mathrm{S} / 160^{\circ} \mathrm{E}$ (Fig. $4-$ March panel), may trigger a barotropic circulation around these TPs (Fig. 7), like the one observed in the reanalysis data (Fig. 6 - March panels). TFs over the western South Pacific, especially near the eastern/southeastern coast of Australia (over the Tasman Sea), may also modulate circulation anomalies around TP3. IFs upperand lower-level circulations show opposite signs over the western subtropical South Pacific (Fig. 7), indicating that the "quasi-baroclinic" circulation around TP3 (Fig. 6 - March panels) was likely induced by heating anomalies over the Tasman Sea (see March rainfall field in Fig. 4). To obtain the 200-hPa anticyclonic circulation and 850-hPa cyclonic circulation around TP4, as observed in Fig. 6 (March panels), the IFs results point out that cooling anomalies over most parts of the Pacific Ocean and Australia are necessary. Because IFs circulation anomalies over the western South Pacific all have signs of the same polarity for TP4, the effects of the dipole-like rainfall pattern on TP4 are likely smoothed. This is because the same sign polarity indicates conflicting influences, in this case, showing that the teleconnection pattern action centres around TPs 1-4 are not equally excited by the dipole-like rainfall pattern. The IFs results for TP4 also show that the local effects associated with heating anomalies over the tropical South Atlantic (March panel in Fig. 4) contribute to generating the baroclinic circulation observed in the reanalysis data (Fig. 6 - March panels). Regarding the effects of TFs on circulation around TP5, the IFs fields indicate that heating anomalies associated with heavy rainfall in the western-central equatorial Pacific likely modulate circulation anomalies over the region near the northern coast of NEB (Fig. 7). Local TFs associated with deep diabatic heating anomalies, on the other hand, do not seem to affect the local circulation. This is indicated by opposite $850-\mathrm{hPa}$ and $200-\mathrm{hPa}$ IFs circulation anomalies (baroclinic circulation) over the northern coast of NEB and adjacent equatorial Atlantic, which contrast those observed in reanalysis data (Fig. 6 - March panels).

The IFs results (Fig. 7), along with the GPCP rainfall data (Fig. 4 - March panel), suggest that deep diabatic heating anomalies (TFs) in four regions may have contributed the most to above-normal rainfall in

434 NEB in March 2019. These regions comprise the following areas: $\sim 5^{\circ} \mathrm{S}-7.5^{\circ} \mathrm{N} / 150^{\circ} \mathrm{E}-170^{\circ} \mathrm{W}$ (TF1); $\sim 20^{\circ} \mathrm{S}-5^{\circ} \mathrm{S} / 155^{\circ} \mathrm{E}-170^{\circ} \mathrm{E}$ (TF2); $40^{\circ} \mathrm{S}-25^{\circ} \mathrm{S} / 152^{\circ} \mathrm{E}-168^{\circ} \mathrm{E}$ (TF3); and $\sim 35^{\circ} \mathrm{S}-15^{\circ} \mathrm{S} / 43^{\circ} \mathrm{W}-10^{\circ} \mathrm{W}$ (TF4). The way this hypothesis was tested is explained next.

\subsection{Vertical and horizontal distributions of thermal forcings}

The vertical and horizontal distributions of TFs 1-4, incorporated into the model's temperature tendency equation, are shown in Fig. 8. Their respective peaks are $13.1 \mathrm{~K} /$ day (at $500 \mathrm{hPa}$ ), $-3.6 \mathrm{~K} /$ day (at $400 \mathrm{hPa}$ ), $4.6 \mathrm{~K} /$ day (at $400 \mathrm{hPa}$ ), and $3.1 \mathrm{~K} /$ day (at $500 \mathrm{hPa}$ ). We considered, in addition, three forcing 
nodes, two peaking in the lower troposphere $(700 \mathrm{hPa}$ and $850 \mathrm{hPa})$ and one in the upper troposphere (300 rainfall anomalies to the north of NEB; its associated area comprises $\sim 2.5^{\circ} \mathrm{S}-7.5^{\circ} \mathrm{N} / 48^{\circ} \mathrm{W}-32^{\circ} \mathrm{W}$ (Fig. 8). The other one relates to positive rainfall anomalies over the entire equatorial Atlantic, and is associated with the Intertropical Convergence Zone (ITCZ) cloud band (not shown). The node peaking in the upper troposphere $(300 \mathrm{hPa})$ relates to deep heating anomalies (heavy rainfall) over the northern coast of NEB (not shown). As shown later, the 850-hPa ZASTRF response over the tropical South Atlantic slightly improves when considering TF5. In contrast, the simulations that considered shallow heating anomalies over the entire equatorial Atlantic and deep heating anomalies over the northern coast of NEB did not provide additional insights into the modulation of atmospheric circulations associated with the above-normal rainfall in NEB (not shown). Therefore, we will not discuss the latter two simulations.

\subsection{Modelled ZASTRF anomalies}

To confirm the IFs results and, thus, assess the origin of the atmospheric circulation anomalies that most contributed to above-normal rainfall in NEB in March 2019, we carried out a set of model experiments that considered the following combinations among the different TFs (diabatic heating anomalies - Fig. 8): (i) TFs 2 and 3; (ii) TFs 2-4; (iii) TFs 1-4; and (iv) TFs 1-5. Because the dynamical framework within the LBM employed is simplified, we only focussed on the qualitative aspect of the model results.

The dipole-like TF over the western South Pacific (TF2+TF3 in Fig. 8) generated a teleconnection pattern that connects the extratropical South Pacific to South Atlantic (TF2+TF3 in Fig. 9). These circulation anomalies have a barotropic structure over the central-southeastern South Pacific and a baroclinic structure over the South America-South Atlantic sector. Experiments using TF2 and TF3 separately showed that TF2 generated circulation anomalies over the South Atlantic through tropical wave dispersion, whilst TF3 triggered extratropical circulation anomalies (not shown). By combining TF4 with TF2 and TF3, results improve and show a baroclinic circulation over the South Atlantic (TF2+TF3+TF4 in Fig. 9) that more closely resembles the one observed in the reanalysis data (compare to March panels of Fig. 6 - note that colour scales are different to allow better visualisation). Such improvement indicates that this baroclinic circulation is modulated by enhanced rainfall (more condensation heating - TF4 in Fig. 8) in the tropical South Atlantic, which, in turn, is likely caused by the warmer SST underneath (Fig. 4). The inclusion of TF1 as the fourth model forcing generates upper-level $(200 \mathrm{hPa})$ positive ZASTRF anomalies to the north of NEB northern coastline (TF1+TF2+TF3+TF4 in Fig. 9), as seen in the reanalysis data (Fig. 6). When used as the only model forcing, TF1 (diabatic heating anomalies over the equatorial Pacific - Fig. 8) induces a baroclinic circulation over the tropical South Atlantic (cyclonic at $200 \mathrm{hPa}$ and anticyclonic at $850 \mathrm{hPa}$ - not shown). This circulation pattern contrasts the one observed in the reanalysis data (Fig. 6). Similar results were obtained by Grimm (2019), who employed a barotropic vorticity model forced by divergence sources. By considering the five TFs together, the lower-level circulation $(850 \mathrm{hPa})$ over the equatorial Atlantic improves slightly (TF1+TF2+TF3+TF4+TF5 in Fig. 9), resembling the one seen in the reanalysis data a bit more (Fig. 
6). Therefore, this set of experiments suggests that remote and local forcings jointly modulated the circulation anomalies that resulted in above-normal rainfall in NEB, as indicated by the IFs results.

\section{MJO contributions to the MAM 2019 rainfall in NEB}

To further explore mechanisms that may have led to above-normal rainfall in NEB in MAM 2019, we examined MJO-related conditions in that period. Fig. 10 shows the RMM diagram (Wheeler and Hendon 2004) for March, April, and May 2019. MJO phases 2 and 3 occurred in the first five days of March and the period 20-27 April. These MJO phases increase the chances of heavier rainfall in NEB (Alvarez et al. 2016; Grimm 2019) - we note that the effects associated with a given MJO phase may last up to about ten days after this phase ends (Seo and Son 2012; Seo and Lee 2017), which likely prolonged the influence of the effects related to MJO phases 2 and 3 on rainfall in NEB in March 2019. In fact, March was the wettest month of MAM 2019 in the northern portion of NEB, with $~ 60 \%$ of the weather stations analysed presenting extreme rainfall (Fig. 5). In April 2019, extreme rainfall occurred at $\sim 40 \%$ of the stations. MJO-related convection locates in more northern latitudes from April to September (Adames et al. 2016), accompanying the ITCZ cloud band displacement. This may have contributed to decreasing the number of stations that recorded extreme rainfall in April 2019, relative to the previous month. Although MJO phase 2 took place in the last two days of May 2019, MJO-related convection does not seem to have influenced rainfall in NEB substantially in that month.

As MJO-related convection seems to have played a more decisive role in NEB rainfall amounts in March 2019, in comparison to the subsequent two months, we now focus on that month and analyse OLR anomalies filtered at different timescales. Low-frequency signals ( $>90$ days) by themselves do not explain all unfiltered OLR anomalies (Fig. 11), suggesting a contribution of oscillations at other timescales to the modulation of atmospheric convection processes. Sub-seasonal signals (30-90 days) for March 2019 indicate reduced convection over NEB, on average, except right over part of the NEB northern coastline. Positive OLR anomalies (reduced convection) over the western tropical Pacific $\left(\sim 10^{\circ} \mathrm{S}-15^{\circ} \mathrm{S}\right)$ at this timescale seem to reinforce low-frequency anomalies over that area. This reinforcement results in anomalous upper- and lower-level circulation conditions that favour the formation of an anticyclone and a cyclone, respectively, over eastern South America and part of the South Atlantic, as found in the model response to TF2 (not shown). As a consequence, such circulation conditions favour anomalous rainfall occurrence in NEB, as previously stated. In opposition to monthly-averaged sub-seasonal signals (30-90 days), those averaged over the first ten days of March 2019 indicate that convection was taking place over the northern portion of NEB. These days were, therefore, the period in which sub-seasonal OLR anomalies over NEB contributed to strengthening low-frequency signals, which resulted in above-normal rainfall in that region. Thus, MJO-related sub-seasonal signals very likely contributed to inhibiting deep atmospheric convection formation over the western tropical Pacific (TF2 region in Fig. 8) during March, as a whole, and to developing convection over NEB during the first ten days of the month. 


\section{Conclusions}

Understanding the differences between rainfall conditions during El Niño events is essential to water resources management, agriculture, livestock, and the safety of people and infrastructure. In 2019,

521 NEB experienced heavy rainfall in autumn (except for the easternmost portion), contrasting the dry 522 conditions that typically take place during El Niños. To investigate this rainfall anomaly, we analysed 523 atmospheric and oceanic conditions using several datasets, which allowed us to realise that above-normal 524 rainfall in NEB in autumn 2019 was likely associated with three main combined factors; these are: (1) the 525 weak intensity of the 2019 El Niño (as stated by Johnson et al. 2019 and Hu et al. 2020); (2) local and 526 remote diabatic heating anomalies, especially over the western South Pacific and tropical South Atlantic; 527 and (3) MJO fluctuations during the first ten days of March 2019.

528 As reported in previous work, the $2019 \mathrm{EI}$ Niño was only weak and associated with an anomalous SST gradient between the western and central equatorial Pacific waters (Johnson et al. 2019). Such a gradient delayed the El Niño-related ocean-atmosphere coupling development (Johnson et al. 2019), contributing to different impacts in remote areas from those expected during these events. In certain regions, such as NEB, atmospheric conditions behaved oppositely those generally observed during El Niños. Concurrent diabatic heating anomalies over several regions during March 2019 resulted in anticyclonic and cyclonic circulations in the upper and lower troposphere, respectively, over the tropical

535 South Atlantic that induced ascending motion over NEB. Deep cooling anomalies (below-normal rainfall) were observed over the tropical South Pacific, whereas deep heating anomalies (heavier rainfall) occurred near the eastern/southeastern coast of Australia (over the Tasman Sea). Local effects resulted mainly from deep heating anomalies over the tropical South Atlantic. Two more thermal forcings contributed to the circulation that affected rainfall over NEB in March 2019. Deep heating anomalies over the equatorial Pacific influenced mostly the upper-level $(200 \mathrm{hPa})$ circulation over the seaward area to the north of NEB, whilst

541 shallow cooling anomalies over the equatorial Atlantic, to the north of NEB northern coast, impacted chiefly

542 the lower-level $(850 \mathrm{hPa})$ circulation over the tropical South Atlantic. All these anomalous thermal forcings 543 combined generated deep convection over NEB and caused anomalously heavy rainfall, especially in the 544 northern portion. MJO phases 2 and 3 coincided with sub-seasonal oscillations that intensified low545 frequency atmospheric convection anomalies over the western Pacific in March 2019 and over NEB during 546 the first ten days of the month, suggesting, therefore, an influence of MJO-related atmospheric convection 547 on NEB rainfall in that period.

548 Daily rainfall data may help elucidate how MJO fluctuations contributed to rainfall in NEB in autumn 549 2019. For instance, $\sim 39 \%$ of the March 2019 accumulated rainfall at São Luís station (321.6 mm, out of $550818.2 \mathrm{~mm}$ ) occurred during the first ten days of the month (not shown), when MJO phases were favourable 551 to increased rainfall in the region. This rainfall amount summed to that of an isolated event on 24 March $5522019(234.4 \mathrm{~mm})$ totalises $\sim 68 \%$ of the accumulated rainfall in that month $(556.0 \mathrm{~mm})$. Relationships 
553 between rainfall in NEB and the ITCZ cloud band during the period analysed here are also worthy of 554 investigation, given that previous studies have found a significant correlation between them (e.g., Utida et 555 al. 2019). A more complex numeric model than the one we employed here, which allows for using SST 556 fields as boundary conditions, may provide more realistic atmospheric responses regarding how equatorial 557 Atlantic warm SST influences the ITCZ cloud band and, consequently, rainfall in NEB. Nevertheless, our 558 results complement findings of the previous studies that characterised less common El Niño events (e.g., 559 McPhaden 2015; Johnson et al. 2019; Hu et al. 2020), marked by ocean-atmosphere decoupling at initial 560 stages, such as those that occurred in 1979-1980, 2004-2005, 2014-2015, and 2018-2019 (Hu et al. 561 2020). Our results also support the conclusion by Hu et al. (2020) that states that El Niño-related rainfall 562 anomalies cannot be predicted accurately based solely on SST anomalies in the tropical Pacific. 563 Atmosphere-ocean coupling is crucial to trigger remote rainfall anomalies. Even when the coupling takes 564 place, like during the period analysed here, rainfall anomalies may not follow the expected pattern for El 565 Niño. This rainfall behaviour has been reported here, reinforcing how much ENSO-related anomalies matter 566 to rainfall occurrence and intensity in NEB. Besides the ENSO's phase (EI Niño or La Niña) and flavour 567 (canonical or Modoki), the intensity of its associated anomalies is of paramount importance to determine 568 whether drought or above-normal rainfall should be expected in NEB.

\section{Acknowledgements}

572 The authors are thankful to INMET (www.inmet.gov.br), ECMWF

573 (https://apps.ecmwf.int/datasets/data/interim-full-moda/levtype=sfc/),

574 (https://psl.noaa.gov/data/gridded/data.noaa.ersst.v5.html,

575 https://psl.noaa.gov/data/gridded/data.gpcp.html, $\quad$ and 576 https://psl.noaa.gov/data/gridded/data.interp_OLR.html) for providing the data employed in this research.

577 We also thank Dr Steven Woolnough, for providing the code to plot the RMM diagram, Dr José Aravéquia, 578 for providing the code to compute influence functions, Dr Michiya Hayashi and Dr Masahiro Watanabe, for 579 providing the LBM code (https://ccsr.aori.u-tokyo.ac.jp/ /bm/sub/lbm.html), and the reviewers, for the 580 constructive comments.

584 Adames ÁF, Wallace JM, Monteiro JM (2016) Seasonality of the structure and propagation characteristics 585 of the MJO. J. Atmos. Sci. 73:3511-3526. https://doi.org/10.1175/JAS-D-15-0232.1 
(new version 2.3) and a review of 2017 global precipitation. Atmosphere 9(4)138.

590 https://doi.org/10.3390/atmos9040138

Allen MP (1997) The $t$ test for the simple regression coefficient. In: Understanding regression analysis. Springer, Boston, MA. 66-70. https://doi.org/10.1007/978-0-585-25657-3_14

Alvarez MS, Vera CS, Kiladis GN, Liebmann B (2016) Influence of the Madden Julian Oscillation on precipitation and surface air temperature in South America. Clim. Dyn. 46:245-262. https://doi.org/10.1007/s00382-015-2581-6

Ambrizzi T, Hoskins BJ (1997) Stationary Rossby-wave propagation in a baroclinic atmosphere. Q. J. R. Meteorol. Soc. 123(540):919-928. https://doi.org/10.1002/qj.49712354007 Bjerknes J (1961) "El Niño" study based on analysis of ocean surface temperatures 1935-57. Inter-Am. Trop. Tuna Comm. Bull. 5(3):217-303. Bjerknes J (1966) A possible response of the atmospheric Hadley circulation to equatorial anomalies of ocean temperature. Tellus 18(4):820-829. https://doi.org/10.1111/j.2153-3490.1966.tb00303.x

Branstator G (1985) Analysis of general circulation model sea-surface temperature anomaly simulations using a linear model. Part I: forced solutions. Journal of the Atmospheric Sciences 42(21): 2225-2241. https://doi.org/10.1175/1520-0469(1985)042<2225:AOGCMS>2.0.CO;2

Cai W, Cowan T (2008) Dynamics of late autumn rainfall reduction over southeastern Australia. Geophys. Res. Lett. 35(9):L09708. https://doi.org/10.1029/2008GL033727

618 Cai W, McPhaden MJ, Grimm AM, Rodrigues RR, Taschetto AS, Garreaud RD, Dewitte B, Poveda G, Ham 619 Y-G, Santoso A, Ng B, Anderson W, Wang G, Geng T, Jo H-S, Marengo JA, Alves LM, Osman M, Li S, Wu 620 L, Karamperidou C, Takahashi K, Vera C (2020) Climate impacts of the El Niño-Southern Oscillation on 621 South America. Nat. Rev. Earth Environ. 1:215-231. https://doi.org/10.1038/s43017-020-0040-3 Cai W, van Rensch P, Cowan T (2011) Teleconnection pathways of ENSO and the IOD and the mechanisms impacts on Australian rainfall.

J. Clim. 24:3910-3923. 
Cane MA (2005) The evolution of El Niño, past and future. Earth Planet. Sci. Lett. 230(3-4):227-240. https://doi.org/10.1016/j.epsl.2004.12.003

Chase TN, Pielke Sr RA, Avissa R (2006) Teleconnections in the Earth System. In: Anderson MG (ed) Encyclopedia of Hydrological Sciences. Wiley, Hoboken. https://doi.org/10.1002/0470848944.hsa190

Davey MK, Brookshaw A, Ineson S (2014) The probability of the impact of ENSO on precipitation and nearsurface temperature. Clim. Risk Manag. 1:5-24. https://doi.org/10.1016/j.crm.2013.12.002

Dee DP et al (2011) The ERA-Interim reanalysis: configuration and performance of the data assimilation system. Q. J. R. Meteorol. Soc. 137:553-597. https://doi.org/10.1002/qj.828

Duchon CE (1979) Lanczos filtering in one and two dimensions. J. Appl. Meteorol. Climatol.18(8):10161022. https://doi.org/10.1175/1520-0450(1979)018<1016:LFIOAT>2.0.CO;2

Giovannettone J, Paredes-Trejo F, Barbosa H, dos Santos CA, Kumar TVL (2020) Characterization of links

643 between hydro-climate indices and long-term precipitation in Brazil using correlation analysis. Int. J.

644 Climatol. 40(13):5527-5541.https://doi.org/10.1002/joc.6533

Grimm AM (2003) The El Niño impact on the summer monsoon in Brazil: regional processes versus remote influences. J. Clim. 16(2):263-280. https://doi.org/10.1175/1520-0442(2003)016<0263:TENIOT>2.0.CO;2

Grimm AM (2011) Interannual climate variability in South America: impacts on seasonal precipitation, extreme events, and possible effects of climate change. Stoch Environ Res Risk Assess 25:537-554. https://doi.org/10.1007/s00477-010-0420-1

Grimm AM (2018) South American monsoon and its extremes. In: Vuruputur V, Sukhatme J, Murtugudde

654 R, Roca R (eds) Tropical extremes: natural variability and trends. Elsevier, Amsterdam, Chapter 3, pp 51655 93. https://doi.org/10.1016/B978-0-12-809248-4.00003-0

Grimm AM (2019) Madden-Julian Oscillation impacts on South American summer monsoon season: 658 precipitation anomalies, extreme events, teleconnections, and role in the MJO cycle. Clim. Dyn., 53(1):907659 932. https://doi.org/10.1007/s00382-019-04622-6 
Grimm AM, Ambrizzi T (2009) Teleconnections into South America from the tropics and extratropics on 666 interannual and intraseasonal timescales. In: Vimeux F, Sylvestre F, Khodri M (eds) Past climate variability 667 in South America and surrounding regions. Developments in paleoenvironmental research. Springer, 668 Dordrecht, pp 159-191. https://doi.org/10.1007/978-90-481-2672-9_7

Grimm AM, Reason CJC (2011) Does the South American monsoon influence African rainfall? J. Clim. 24(4):1226-1238. https://doi.org/10.1175/2010JCLI3722.1

Grimm AM, Reason CJC (2015) Intraseasonal teleconnections between south america and south africa. J. Clim. 28(23):9489-9497. https://doi.org/10.1175/JCLI-D-15-0116.1

Grimm AM, Silva Dias PL (1995) Analysis of tropical-extratropical interactions with influence functions of a barotropic model. J. Atmos. Sci. 52(20):3538-3555. https://doi.org/10.1175/15200469(1995)052<3538:AOTIWI>2.0.CO;2 Houze RA (2014) Cumulonimbus and severe storms. Cloud Dynamics 104:187-236. https://doi.org/10.1016/B978-0-12-374266-7.00008-1

Hu ZZ, McPhaden MJ, Kumar A, Yu JY, Johnson NC (2020) Uncoupled El Niño warming. Geophys. Res. Lett. 47(7):.e2020GL087621. https://doi.org/10.1029/2020GL087621 Huang B, Thorne PW, Banzon VF, Boyer T, Chepurin G, Lawrimore JH, Menne MJ, Smith TM, Vose RS, Zhang H-M (2017) Extended reconstructed sea surface temperature, version 5 (ERSSTv5): upgrades, validations, and intercomparisons. J. Clim. 30(20):8179-8205. https://doi.org/10.1175/JCLI-D-16-0836.1 Jin F, Hoskins BJ (1995) The direct response to tropical heating in a baroclinic atmosphere. J. Atmos. Sci. 52(3):307-319. https://doi.org/10.1175/1520-0469(1995)052<0307:TDRTTH>2.0.CO;2 Johnson NC, L'Heureux ML, Chang C-H, Hu Z-Z (2019) On the delayed coupling between ocean and atmosphere in recent weak El Niño episodes. Geophys. Res. Lett. 46:11416-11425. https://doi.org/10.1029/2019GL084021

698 atmosphere with meridional and vertical shear. J. Atmos. Sci. 43(18):1893-1912. https://doi.org/10.1175/1520-0469(1986)043<1893:ROPWTS>2.0.CO;2 
Kayano MT, Capistrano VB (2014) How the Atlantic multidecadal oscillation (AMO) modifies the ENSO influence on the South American rainfall. Int. J. Climatol. 34(1):162-178. https://doi.org/10.1002/joc.3674

Levine AF, McPhaden MJ, Frierson DM (2017) The impact of the AMO on multidecadal ENSO variability.

L'Heureux ML, Takahashi K, Watkins AB, Barnston AG, Becker EJ, Di Liberto TE, Gamble F, Gottschalck J, Halpert MS, Huang B, Mosquera-Vásquez K, Wittenberg AT (2017) Observing and predicting the 2015/16 El Niño. Bull. Am. Meteorol. Soc. 98(7):1363-1382. https://doi.org/10.1175/BAMS-D-16-0009.1

L'Heureux ML, Thompson DWJ (2006) Observed relationships between the El Niño-Southern Oscillation and the extratropical zonal-mean circulation. J. Clim. 19:276-287. https://doi.org/10.1175/JCLI3617.1

Liebmann B, Smith CA (1996) Description of a complete (interpolated) outgoing longwave radiation dataset. Bull. Am. Meteorol. Soc. 77(6):1275-1277

716

Lin J, Qian TA (2019) A new picture of the global impacts of El Niño-Southern Oscillation. Sci. Rep. 9 17543. https://doi.org/10.1038/s41598-019-54090-5

Liu AZ, Ting M, Wang H (1998) Maintenance of circulation anomalies during the 1988 drought and 1993 floods over the United States. J. Atmos. Sci. 55(17):2810-2832. https://doi.org/10.1175/15200469(1998)055<2810:MOCADT>2.0.CO;2

Livezey RE, Chen WY (1983) Statistical field significance and its determination by Monte Carlo techniques. Mon. Wea. Rev. 111(1):46-59. https://doi.org/10.1175/1520-0493(1983)111<0046:SFSAID>2.0.CO;2 Rev. 128(7):2528-2543. https://doi.org/10.1175/1520-0493(2000)128<2528:EERPOT>2.0.CO;2 J. Atmos. Sci. 28:702-708. https://doi.org/10.1175/1520-0469(1971)028<0702:DOADOI>2.0.CO;2 period. J. Atmos.

Sci. 29:1109-1123. https://doi.org/10.1175/1520- 
737 Madden RA, Julian PR (1994) Observations of the 40-50-day tropical oscillation-a review. Mon. Wea. 738 Rev. 122:814-837. https://doi.org/10.1175/1520-0493(1994)122<0814:OOTDTO>2.0.CO;2

739

740

741

742

743

744

745

746

747

748

749

750

751

752

753

754

755

756

757

758

759

760

761

762

763

764

765

766

767

768

769

770

771

772

773

Majda AJ, Biello JA (2003) The nonlinear interaction of barotropic and equatorial baroclinic Rossby waves. J. Atmos. Sci. 60(15):1809-1821. https://doi.org/10.1175/1520-0469(2003)060<1809:TNIOBA>2.0.CO;2

Mantua NJ, Hare SR (2002) The Pacific Decadal Oscillation. J. Oceanogr. 58:35-44. https://doi.org/10.1023/A:1015820616384

McPhaden MJ (2015) Playing hide and seek with El Niño. Nat. Clim. Change 5:791-795. https://doi.org/10.1038/nclimate2775

McPhaden MJ, Zebiak SE, Glantz MH (2006) ENSO as an integrating concept in Earth science. Science 314(5806):1740-1745. https://doi.org/10.1126/science.1132588

Mo KC, Nogues-Paegle J (2005) Pan-America. Intraseasonal variability in the atmosphere-ocean climate system. Springer Praxis Books (Environmental Sciences). Springer, Berlin, Heidelberg, pp 95-124. https://doi.org/10.1007/3-540-27250-X_4

Neelin JD, Battisti DS, Hirst AC, Jin F-F, Wakata Y, Yamagata T, Zebiak SE (1998) ENSO theory. J. Geophys. Res. Oceans 103(C7):14261-14290. https://doi.org/10.1029/97JC03424

Nicholls N (1985) Towards the prediction of major Australian droughts. Aust. Met. Mag. 33:161-166

Nicholls N (1991) The El Niño / Southern Oscillation and Australian vegetation. Vegetatio 91(1-2):23-36. https://doi.org/10.1007/BF00036045

Nobre GG, Muis S, Veldkamp TI, Ward PJ (2019) Achieving the reduction of disaster risk by better predicting impacts of El Niño and La Niña. Progress in Disaster Science 2:100022. https://doi.org/10.1016/j.pdisas.2019.100022

Rodrigues RR, Haarsma RJ, Campos EJD, Ambrizzi T (2011) The impacts of inter-El Niño variability on the tropical Atlantic and northeast Brazil climate. J. Clim. 24:3402-3422. https://doi.org/10.1175/2011JCLI3983.1

Rodrigues RR, McPhaden MJ (2014) Why did the 2011-2012 La Niña cause a severe drought in the Brazilian Northeast? Geophys. Res. Lett. 41:1012-1018. https://doi.org/10.1002/2013GL058703 
Schumacher C, Houze Jr, RA, Kraucunas I (2004) The tropical dynamical response to latent heating estimates derived from the TRMM precipitation radar. Journal of the Atmospheric Sciences 61(12):13411358. https://doi.org/10.1175/1520-0469(2004)061<1341:TTDRTL>2.0.CO;2

Schumacher C, Zhang MH, Ciesielski PE (2007) Heating structures of the TRMM field campaigns. J. Atmos. Sci. 64(7):2593-2610. https://doi.org/10.1175/JAS3938.1

Seo K-H, Lee HJ (2017) Mechanisms for a PNA-like teleconnection pattern in response to the MJO. J. Atmos. Sci. 74(6):1767-1781. https://doi.org/10.1175/JAS-D-16-0343.1

Seo K-H, Son S-W (2012) The global atmospheric circulation response to tropical diabatic heating associated with the Madden-Julian Oscillation during northern winter. J. Atmos. Sci. 69(1):79-96. https://doi.org/10.1175/2011JAS3686.1

Shimizu MH, Ambrizzi T (2016) MJO influence on ENSO effects in precipitation and temperature over South America. Theor. Appl. Climatol. 124:291-301. https://doi.org/10.1007/s00704-015-1421-2

Shimizu MH, Ambrizzi T, Liebmann B (2017) Extreme precipitation events and their relationship with ENSO and MJO phases over northern South America.

Int. J. Climatol. 37(6):2977-2989.

794 https://doi.org/10.1002/joc.4893

Shimizu MH, Cavalcanti IFA (2011) Variability patterns of Rossby wave source. Clim. Dyn. 37:441-454. https://doi.org/10.1007/s00382-010-0841-z

798

Stan C, Straus DM, Frederiksen JS, Lin H, Maloney ED, Schumacher C (2017) Review of tropicalextratropical teleconnections on intraseasonal time scales. Rev. Geophys. 55(4):902-937. https://doi.org/10.1002/2016RG000538

802

Taschetto AS, England MH (2009) El Niño Modoki impacts on Australian rainfall. J. Clim. 22:3167-3174. 804 https://doi.org/10.1175/2008JCLI2589.1 
811 Tedeschi RG, Grimm AM, Cavalcanti IFA (2016) Influence of Central and East ENSO on precipitation and 812 its extreme events in South America during austral autumn and winter. Int. J. Climatol. 36(15):4797-4814. 813 https://doi.org/10.1002/joc.4670

814

815 Teng H, Branstator G (2019) Amplification of waveguide teleconnections in the boreal summer. Curr Clim 816 Change Rep 5(4):421-432. https://doi.org/10.1007/s40641-019-00150-x

818 Trenberth KE (1997) The definition of el nino. Bulletin of the American Meteorological Society 78(12):27712778. https://doi.org/10.1175/1520-0477(1997)078<2771:TDOENO>2.0.CO;2

Trenberth KE, Caron JM (2000) The Southern Oscillation revisited: sea level pressures, surface 822 temperatures, and precipitation. J. Clim. 13(24):4358-4365. https://doi.org/10.1175/1520823 0442(2000)013<4358:TSORSL>2.0.CO;2

Trenberth KE, Hurrell JW (1994) Decadal atmosphere-ocean variations in the Pacific. Clim. Dyn. 9(6):303319. https://doi.org/10.1007/BF00204745

Trenberth KE, Solomon A (1993) Implications of global atmospheric spatial spectra for processing and displaying data.

J. Clim.

6(3):531-545. https://doi.org/10.1175/15200442(1993)006<0531:IOGASS>2.0.CO;2

Trenberth KE, Stepaniak DP (2001) Indices of El Niño evolution. J. Clim. 14(8):1697-1701. https://doi.org/10.1175/1520-0442(2001)014<1697:LIOENO>2.0.CO;2

Tseng K-C, Maloney E, Barnes EA (2019) The consistency of MJO teleconnection patterns: an explanation using linear Rossby wave theory. J. Clim. 32:531-548. https://doi.org/10.1175/JCLI-D-18-0211.1

Tseng K-C, Maloney E, Barnes EA (2020) The consistency of MJO teleconnection patterns on interannual time scales. J. Clim. 33(9):3471-3486. https://doi.org/10.1175/JCLI-D-19-0510.1

841 Utida G, Cruz FW, Etourneau J, Bouloubassi I, Schefuß E, Vuille M, Novello VF, Prado LF, Sifeddine A,

842 Klein V, Zular A, Viana JCC, Turcq B (2019) Tropical South Atlantic influence on Northeastern Brazil 843 precipitation and ITCZ displacement during the past 2300 years. Scientific reports 9(1):1-8. 844 https://doi.org/10.1038/s41598-018-38003-6 
Wallace JM, Hobbs PV, McMurdie L, Houze RA (2006) Weather Systems. In: Atmospheric Science - An Introductory Survey, 2nd Edition pp 313-373. https://doi.org/10.1016/B978-0-12-732951-2.50013-2

Watanabe M, Kimoto M. (2000) Atmosphere-ocean thermal coupling in the North Atlantic: A positive feedback. Q. J. R. Meteorol. Soc. 126(570):3343-3369. https://doi.org/10.1002/qj.49712657017.

Wheeler MC, Hendon HH (2004) An all-season real-time multivariate MJO index: development of an index for monitoring and prediction. Mon. Wea. Rev. 132:1917-1932. https://doi.org/10.1175/15200493(2004)132<1917:AARMMI>2.0.CO;2

Wyrtki K (1975) El Niño-the dynamic response of the equatorial Pacific Ocean to atmospheric forcing. J. Phys. Oceanogr. 5:572-584. https://doi.org/10.1175/1520-0485(1975)005<0572:ENTDRO>2.0.CO;2

Yanai M, Esbensen S, Chu JH (1973) Determination of bulk properties of tropical cloud clusters from largescale heat and moisture budgets. J. Atmos. Sci. 30(4):611-627. https://doi.org/10.1175/15200469(1973)030<0611:DOBPOT>2.0.CO;2

Zhang C, Hagos SM (2009) Bi-modal structure and variability of large-scale diabatic heating in the tropics. J. Atmos. Sci. 66(12):3621-3640. https://doi.org/10.1175/2009JAS3089.1

Zhou G (2019) Atmospheric Response to Sea Surface Temperature Anomalies in the Mid-latitude Oceans: A Brief Review. Atmosphere-Ocean 57(5):319-328. https://doi.org/10.1080/07055900.2019.1702499

\section{Figure captions}

875 Fig. 1 Locations of the weather stations in northeastern Brazil from where data were sourced. MA, PI, CE, and RN stand for Maranhão, Piauí, Ceará, and Rio Grande do Norte, respectively

Fig. 2 Linear regressions of austral autumn sea surface temperature (SST), rainfall, and 200-hPa and 850hPa zonally asymmetric streamfunction (ZASTRF) anomalies onto Niño 3.4 index. Hatched areas indicate statistically significant values at the $90 \%$ confidence level according to a two-tailed Student's $t$-test (Allen 1997)

Fig. 3 Linear regressions of austral autumn sea surface temperature (SST), rainfall, and 200-hPa and 850- 
areas indicate statistically significant values at the $90 \%$ confidence level according to a two-tailed Student's $t$-test (Allen 1997)

Fig. 4 Sea surface temperature (left panels) and rainfall (right panels) anomalies for March, April, May, and autumn 2019

Fig. 5 Normalised accumulated rainfall anomalies for March, April, May, and autumn over the period 19792019. Anomalies were calculated from weather station data collected in northeastern Brazil. Dashed grey lines represent \pm 1 standard deviation, and straight grey lines null standard deviation. Vertical dotted lines mark years of extreme El Niños $(1983,1998$, and 2016)

Fig. 6 200-hPa (left panels) and 850-hPa (right panels) zonally asymmetric streamfunction (ZASTRF) anomalies for March, April, May, and autumn 2019. Black dots represent the target points 1-5 (from left to right), where circulation anomalies were assessed using the influence functions and LBM (please refer to Fig. 7 for additional details)

Fig. 7 Influence functions results: 200-hPa (left panels) and $850-\mathrm{hPa}$ (right panels) zonally asymmetric streamfunction (ZASTRF) anomalies for five target points (TP1-TP5 - black dots), considering the March climatological basic state. IFs were applied to modelled ZASTRF anomalies, between $35^{\circ} \mathrm{S}$ and $35^{\circ} \mathrm{N}$ (straight horizontal lines), on the 15th day of simulation. Magenta [green] contours $\left(1 \times 10^{6} \mathrm{~m}^{2} / \mathrm{s}\right)$ indicate positive [negative] ZASTRF anomalies around the TP for positive diabatic heating anomalies. Dashed lines indicate the zero contour

Fig. 8 Vertical and horizontal distributions of the diabatic heating anomalies incorporated into the model's temperature tendency equation. TF stands for thermal forcing

911 Fig. 9 Modelled 200-hPa (left panels) and 850-hPa (right panels) zonally asymmetric streamfunction 912 (ZASTRF) results on the 15th day of simulation considering combinations among the thermal forcings (TFs) $9131,2,3,4$, and 5

915 Fig. 10 RMM diagram for March (blue), April (green), and May (red) 2019. Stars and squares represent the 916 first and last days of the months, respectively. Full circles indicate the other days of the month, in ascending 917 order, connected by straight lines. The central circle indicates an inactive MJO. Each region comprises the 918 two MJO phases that are expected to enhance atmospheric convection over that region 
920 Fig. 11 Mean outgoing longwave radiation (OLR) for March 2019: (upper panel) unfiltered; (upper-middle 921 panel) low-frequency filtered (>90 days); (lower-middle panel) sub-seasonally filtered (30-90 days); and 922 (lower panel) the first ten days of March 2019. Averages were calculated using daily OLR anomalies 


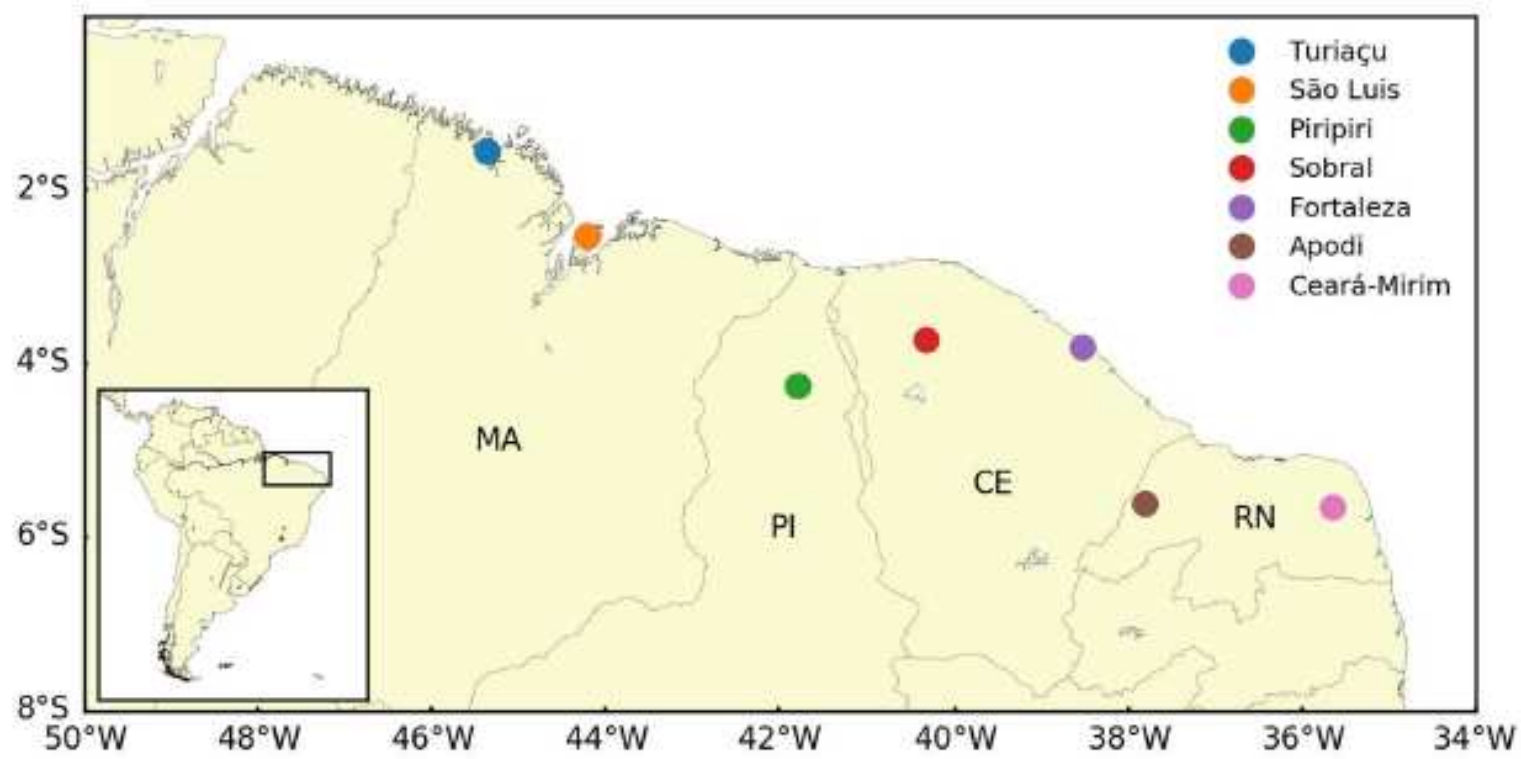

\section{Figure 1}

Locations of the weather stations in northeastern Brazil from where data were sourced. MA, PI, CE, and RN stand for Maranhão, Piauí, Ceará, and Rio Grande do Norte, respectively

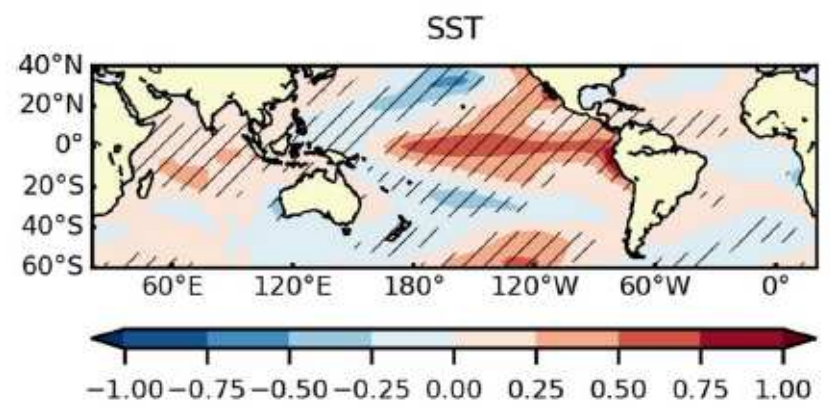

$[\mathrm{K}]$

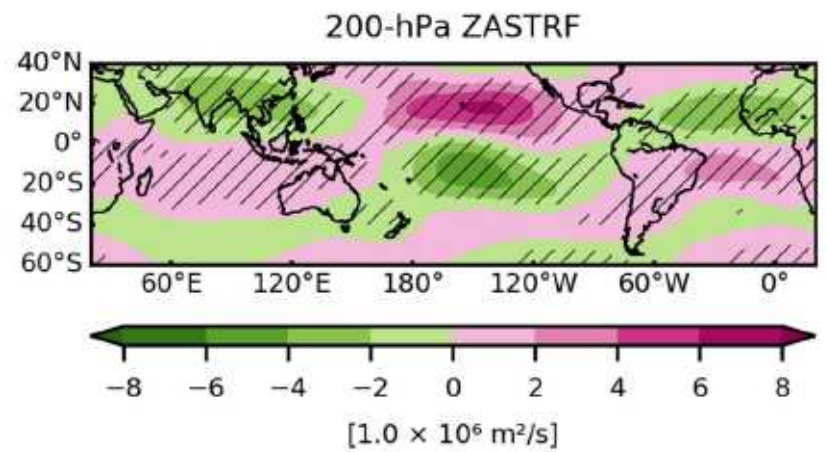

Rainfall

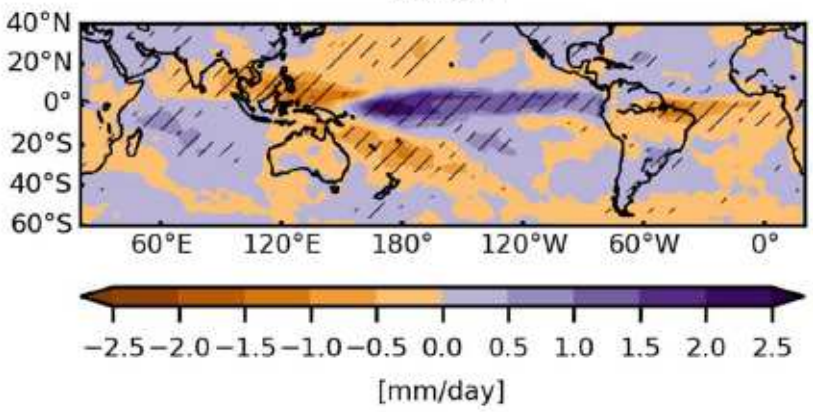

850-hPa ZASTRF

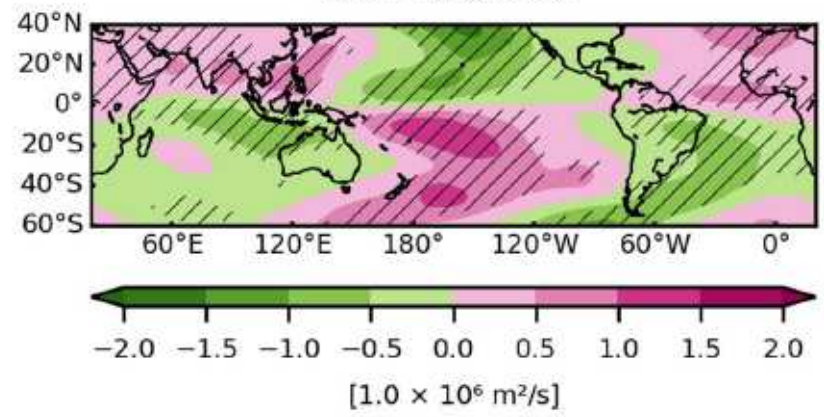

Figure 2 
Linear regressions of austral autumn sea surface temperature (SST), rainfall, and 200-hPa and 850-hPa zonally asymmetric streamfunction (ZASTRF) anomalies onto Niño 3.4 index. Hatched areas indicate statistically significant values at the $90 \%$ confidence level according to a two-tailed Student's t-test (Allen 1997)

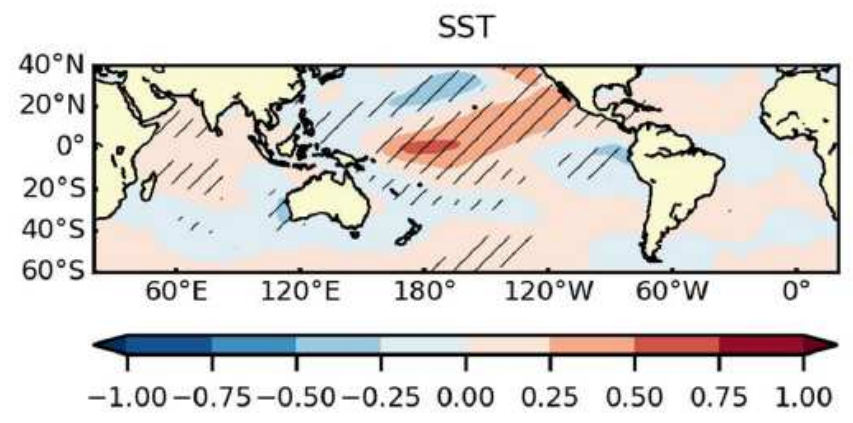

$[\mathrm{K}]$

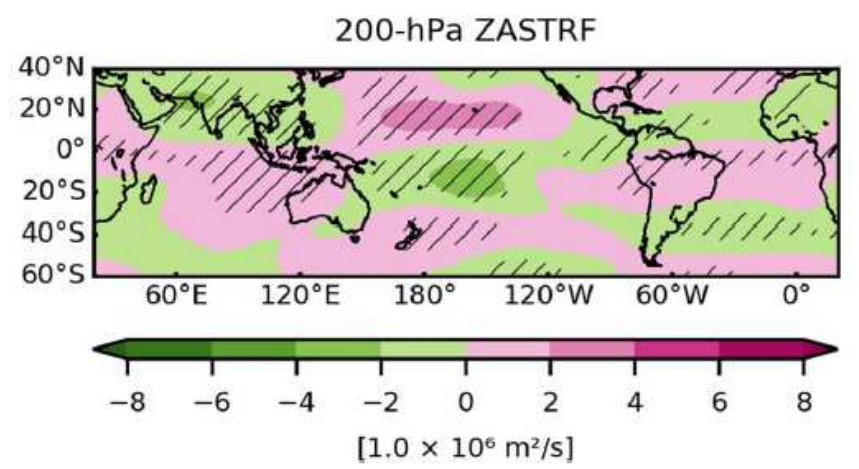

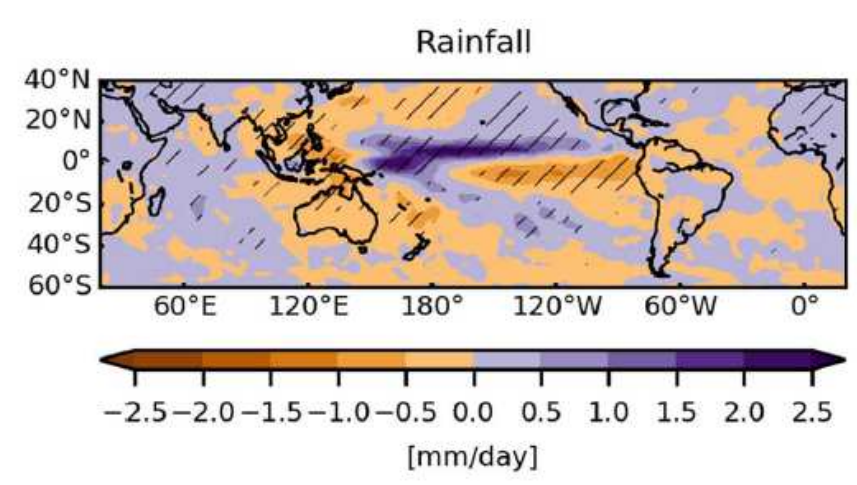

850-hPa ZASTRF

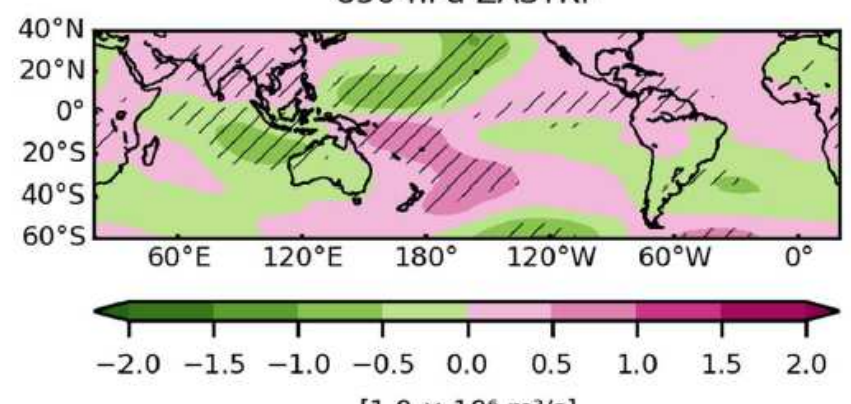

$\left[1.0 \times 10^{6} \mathrm{~m}^{2} / \mathrm{s}\right]$

\section{Figure 3}

Linear regressions of austral autumn sea surface temperature (SST), rainfall, and 200-hPa and 850-hPa zonally asymmetric streamfunction (ZASTRF) anomalies onto El Niño Modoki Index (EMI). Hatched areas indicate statistically significant values at the $90 \%$ confidence level according to a two-tailed Student's t-test (Allen 1997) 
MARCH

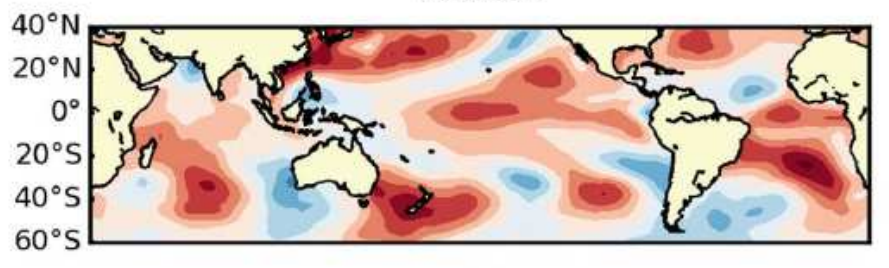

APRIL
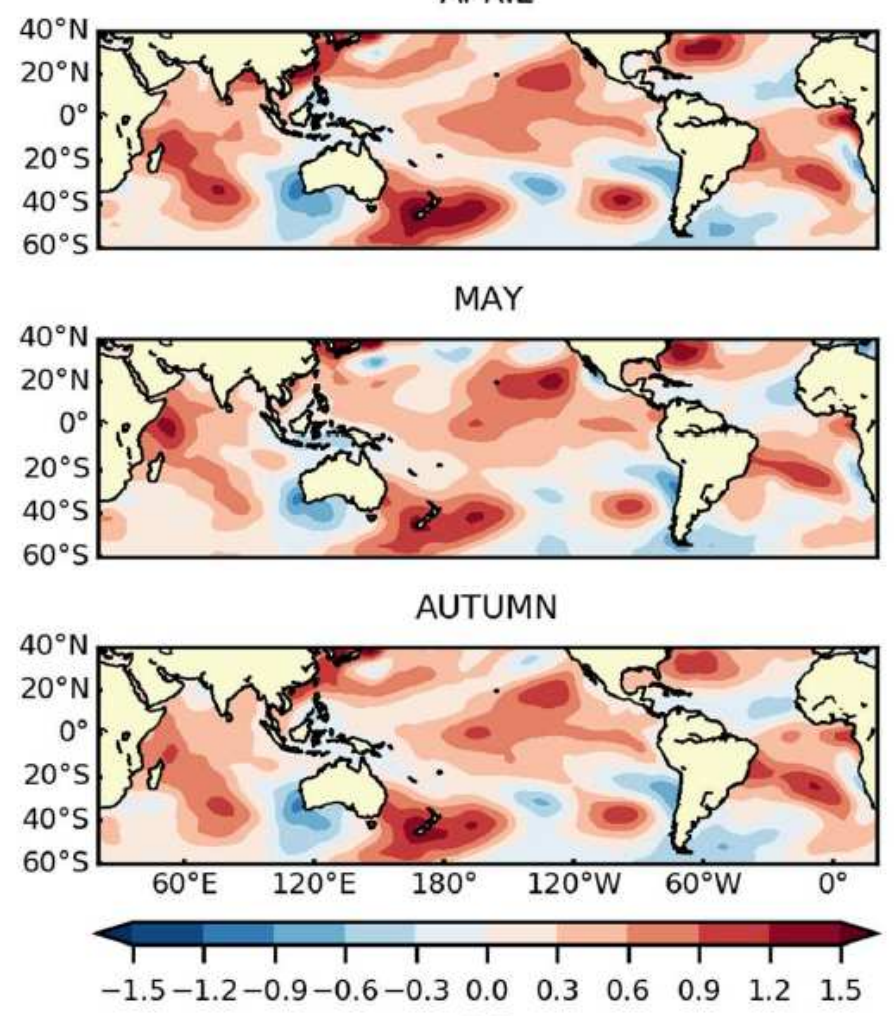

[K]

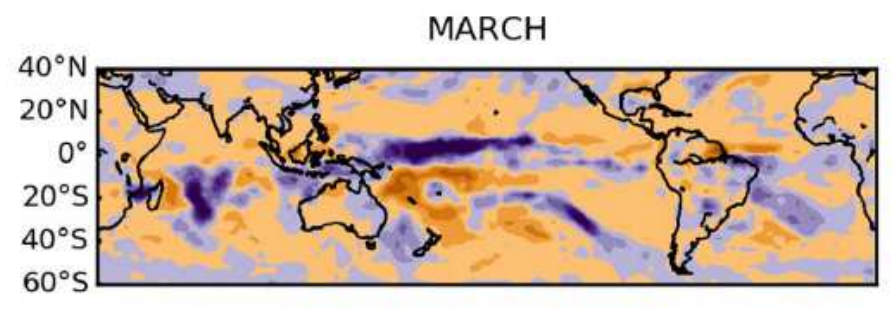

APRIL

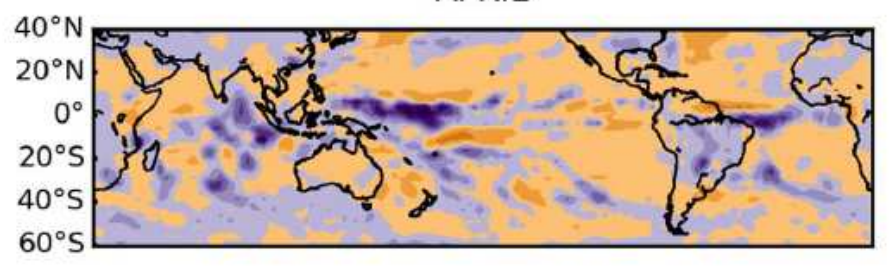

MAY
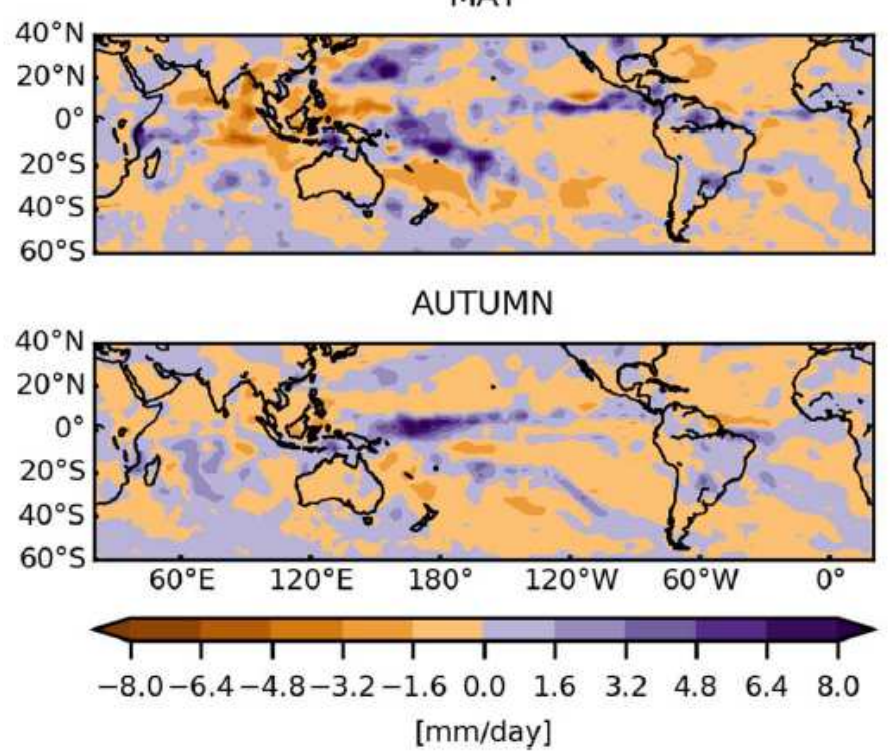

Figure 4

Sea surface temperature (left panels) and rainfall (right panels) anomalies for March, April, May, and autumn 2019 
March
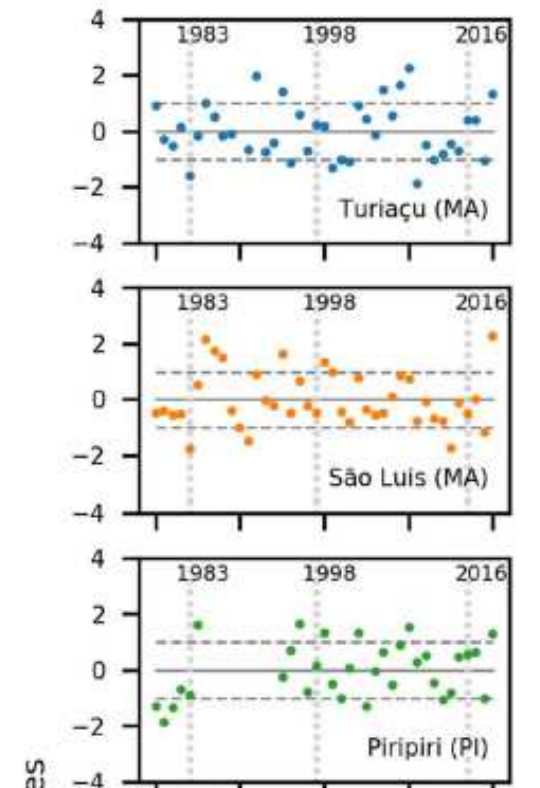

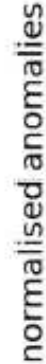

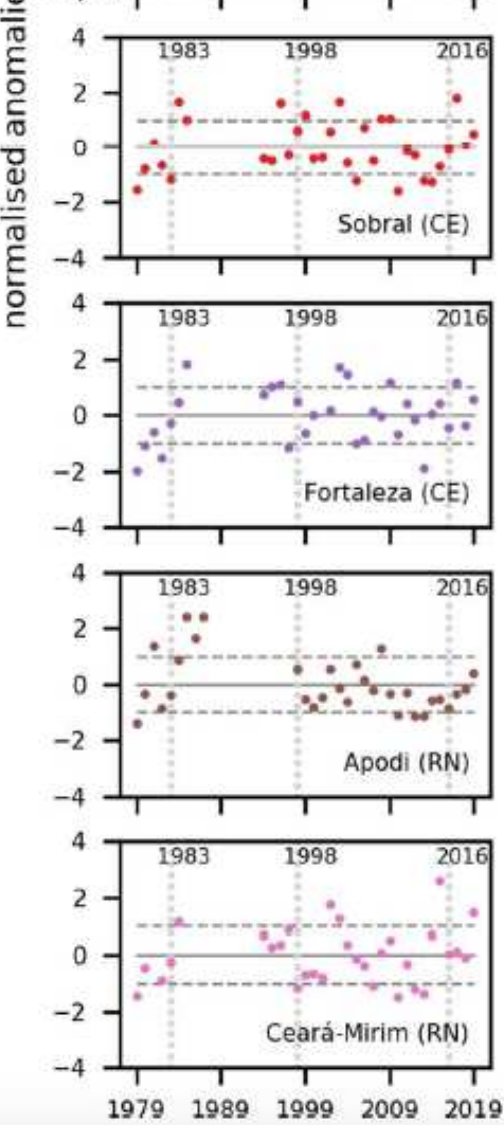

April
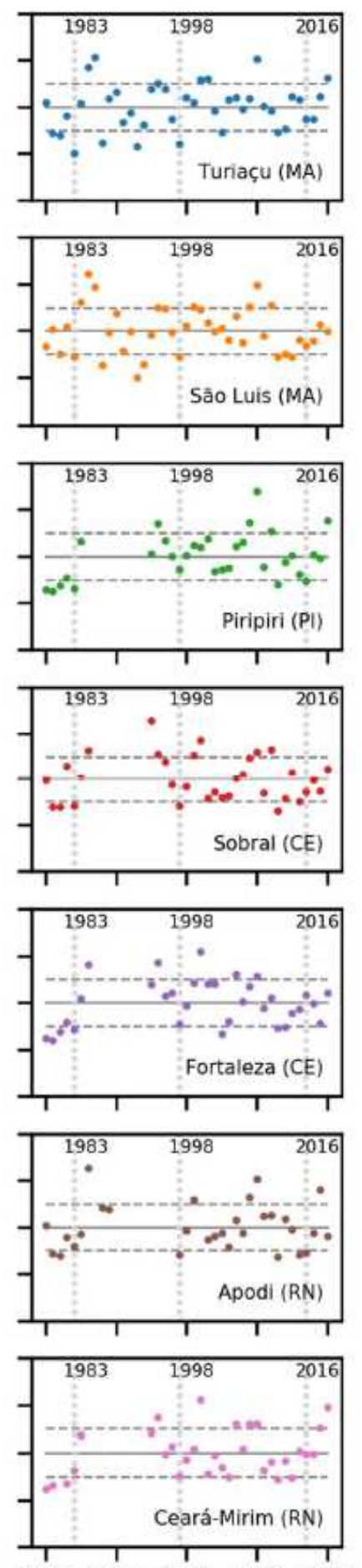

19791989199920092019
May
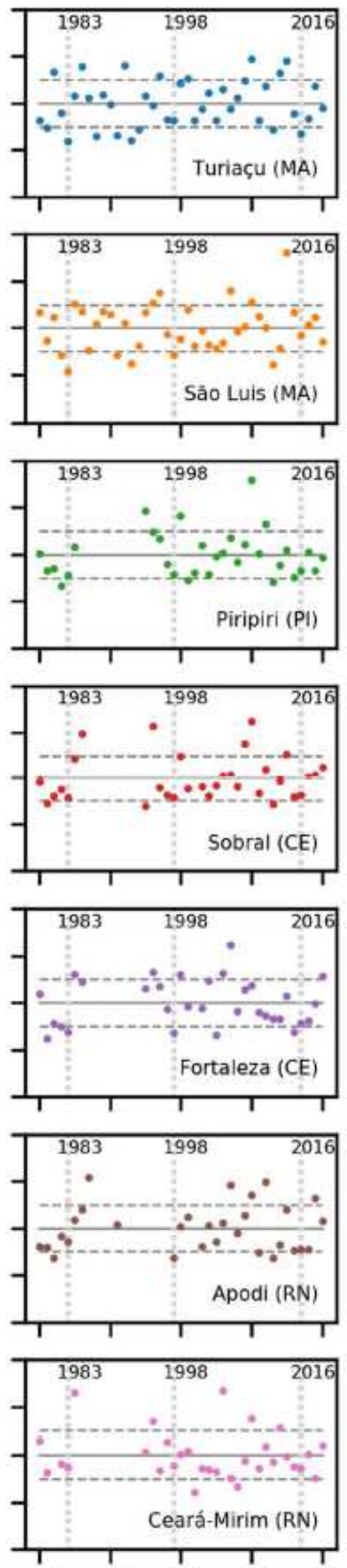

$1979 \quad 1989 \quad 199920092019$
Autumn
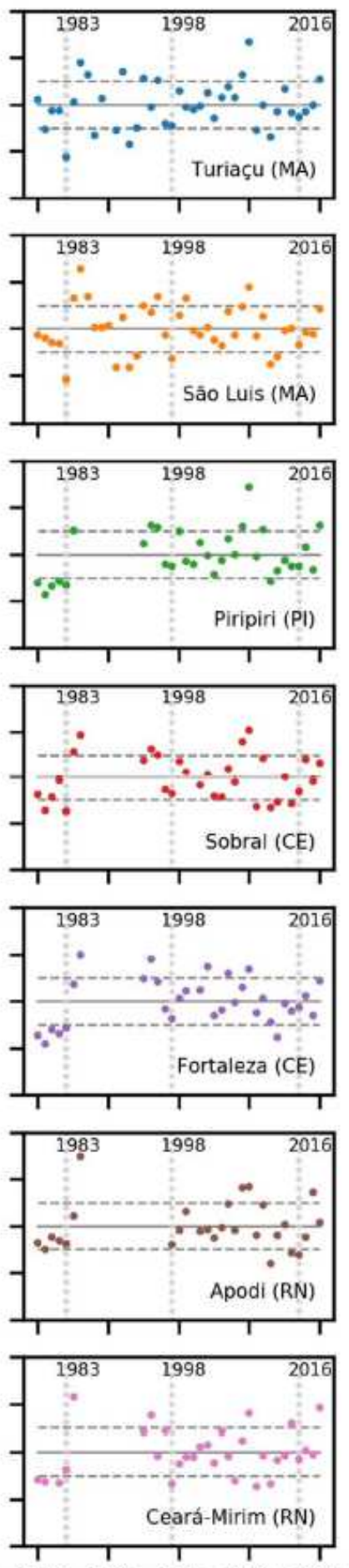

$1979 \quad 1989 \quad 1999 \quad 2009 \quad 2019$

\section{Figure 5}

Normalised accumulated rainfall anomalies for March, April, May, and autumn over the period 19792019. Anomalies were calculated from weather station data collected in northeastern Brazil. Dashed grey lines represent \pm 1 standard deviation, and straight grey lines null standard deviation. Vertical dotted lines mark years of extreme El Niños $(1983,1998$, and 2016) 
MARCH

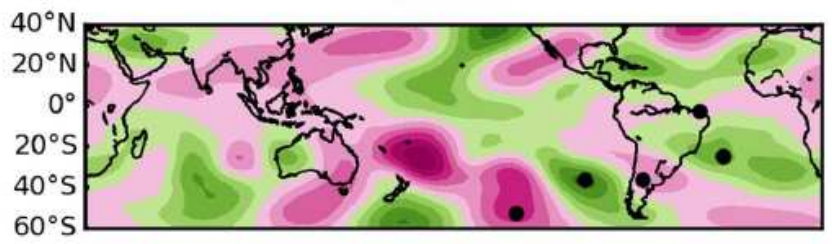

APRIL

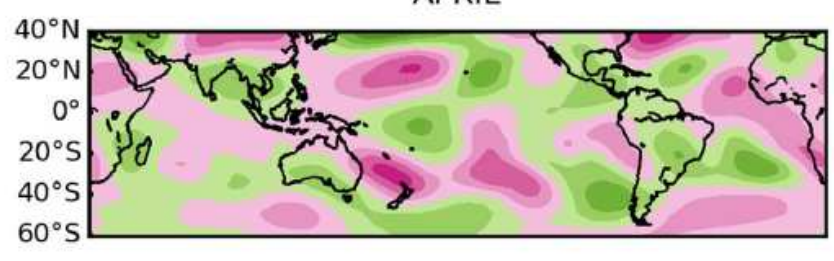

MAY

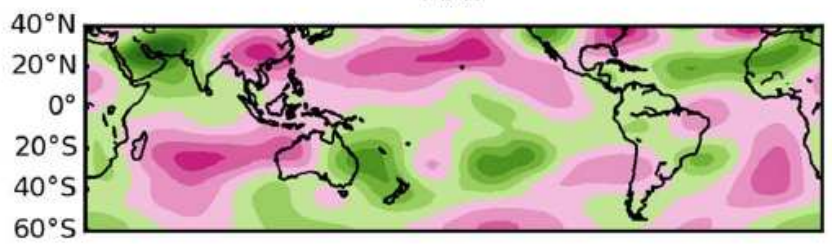

$60^{\circ} \mathrm{S}$ AUTUMN

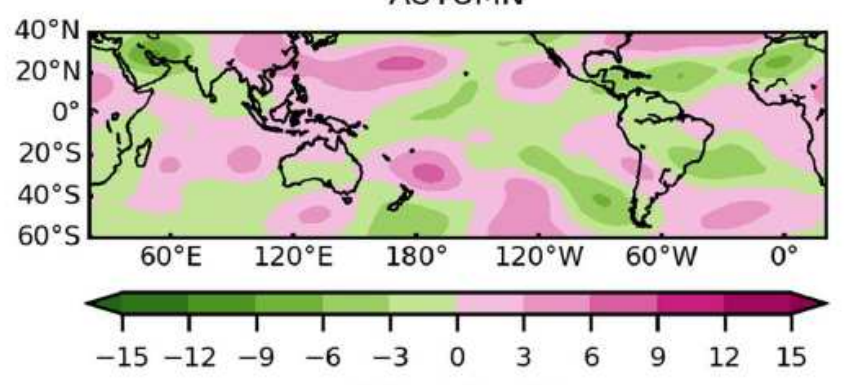

$\left[1.0 \times 10^{6} \mathrm{~m}^{2} / \mathrm{s}\right]$
MARCH

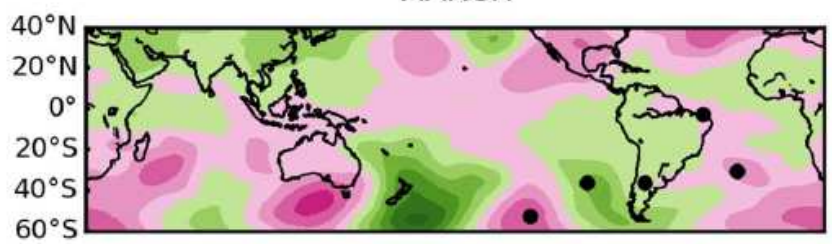

APRIL

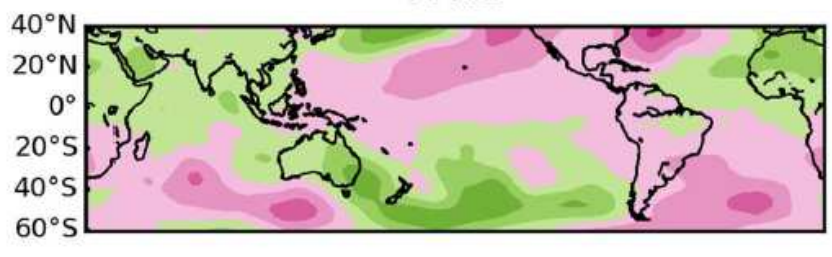

MAY

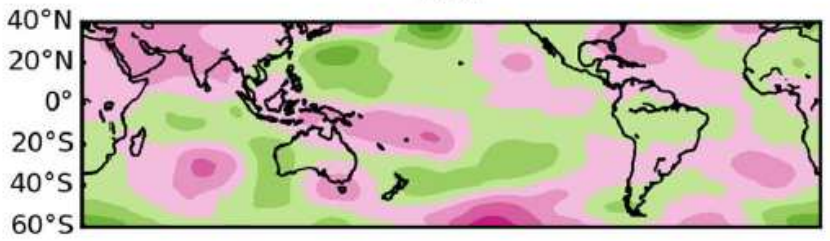

AUTUMN

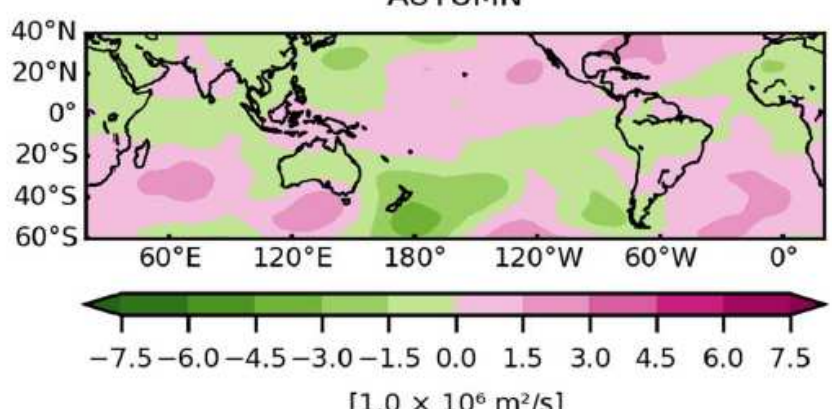

$\left[1.0 \times 10^{6} \mathrm{~m}^{2} / \mathrm{s}\right]$

Figure 6

200-hPa (left panels) and 850-hPa (right panels) zonally asymmetric streamfunction (ZASTRF) anomalies for March, April, May, and autumn 2019. Black dots represent the target points 1-5 (from left to right), where circulation anomalies were assessed using the influence functions and LBM (please refer to Fig. 7 for additional details) 
TP1

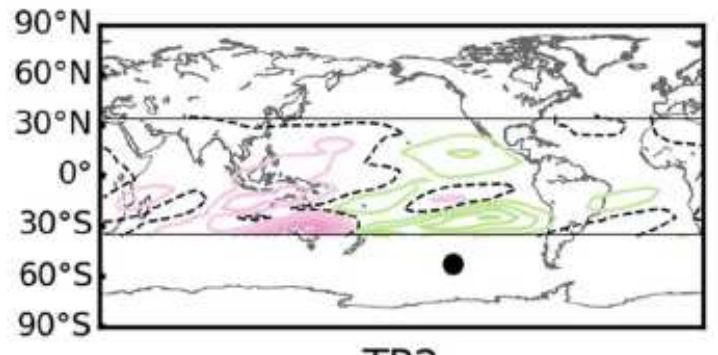

TP2

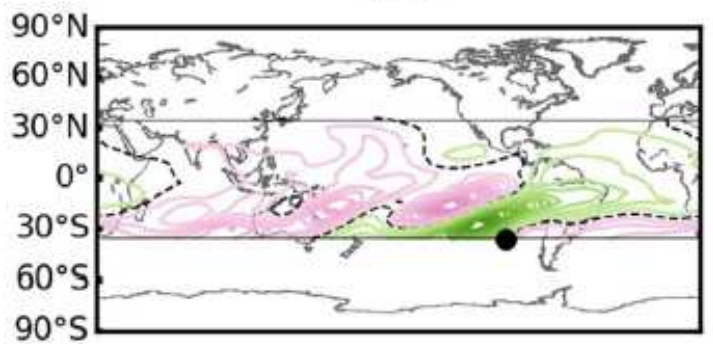

TP3

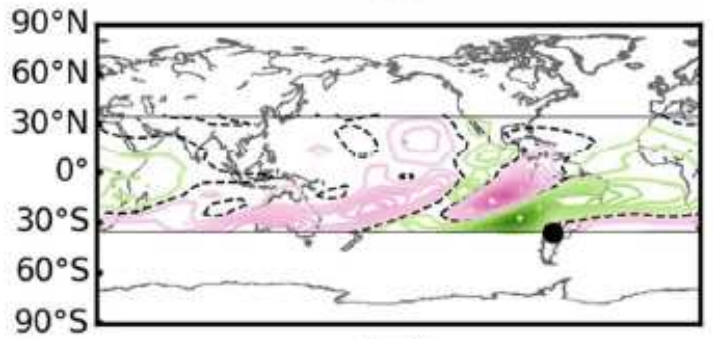

TP4

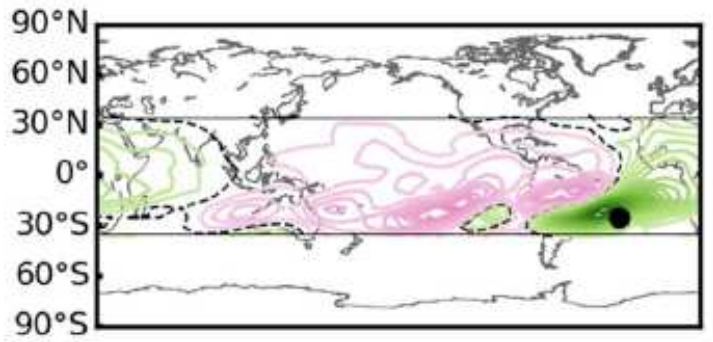

TP5

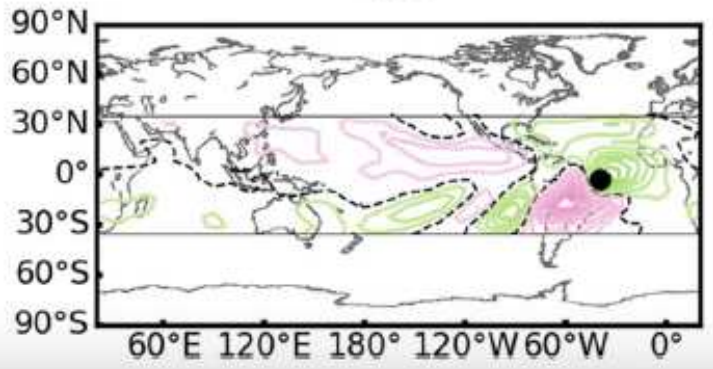

TP1

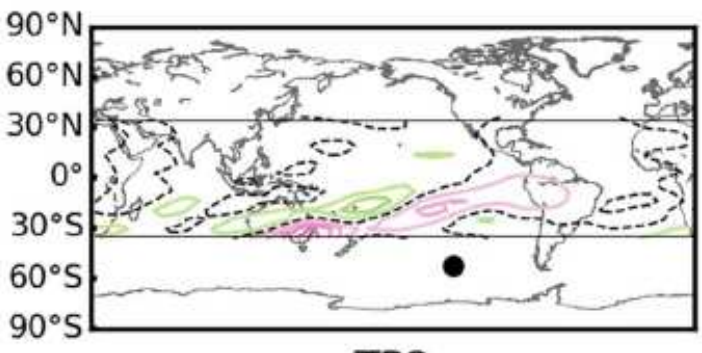

TP2

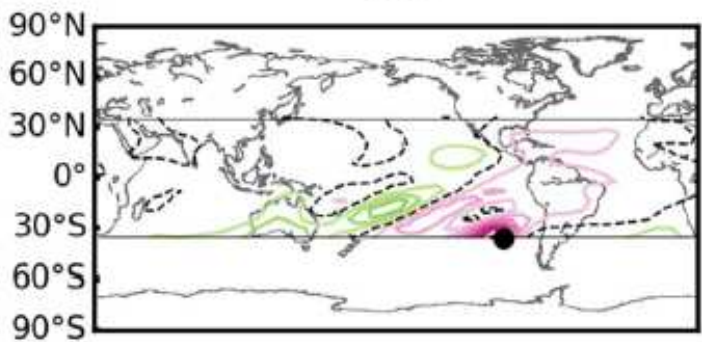

TP3

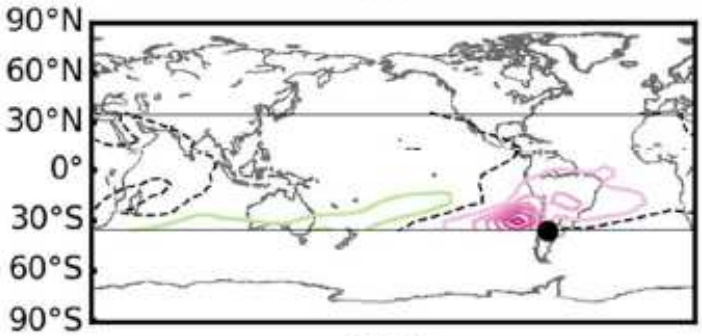

TP4

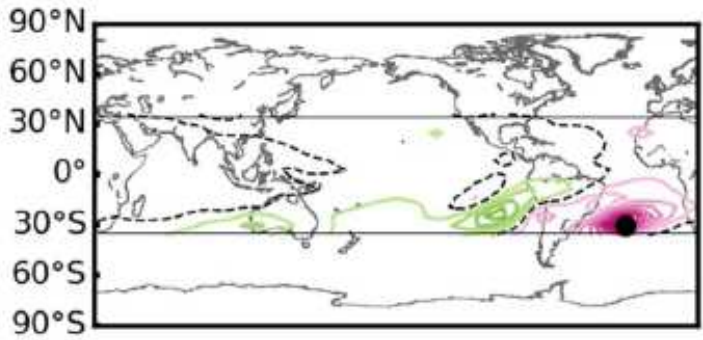

TP5

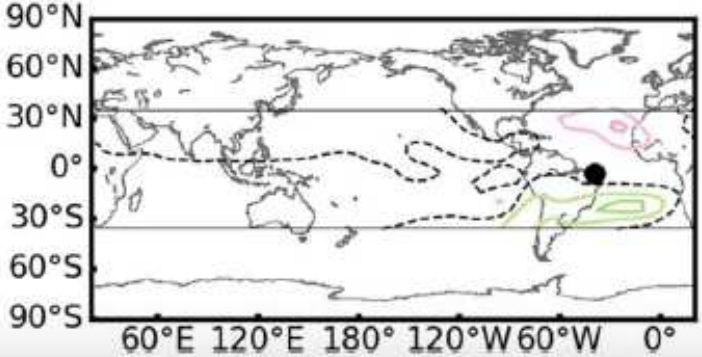

\section{Figure 7}

Influence functions results: $200-\mathrm{hPa}$ (left panels) and $850 \mathrm{hPa}$ (right panels) zonally asymmetric streamfunction (ZASTRF) anomalies for five target points (TP1-TP5 - black dots), considering the March climatological basic state. IFs were applied to modelled ZASTRF anomalies, between $35^{\circ} \mathrm{S}$ and $35^{\circ} \mathrm{N}$ (straight horizontal lines), on the 15th day of simulation. Magenta [green] contours $(1 \times 106 \mathrm{~m} 2 / \mathrm{s})$ 
indicate positive [negative] ZASTRF anomalies around the TP for positive diabatic heating anomalies. Dashed lines indicate the zero contour
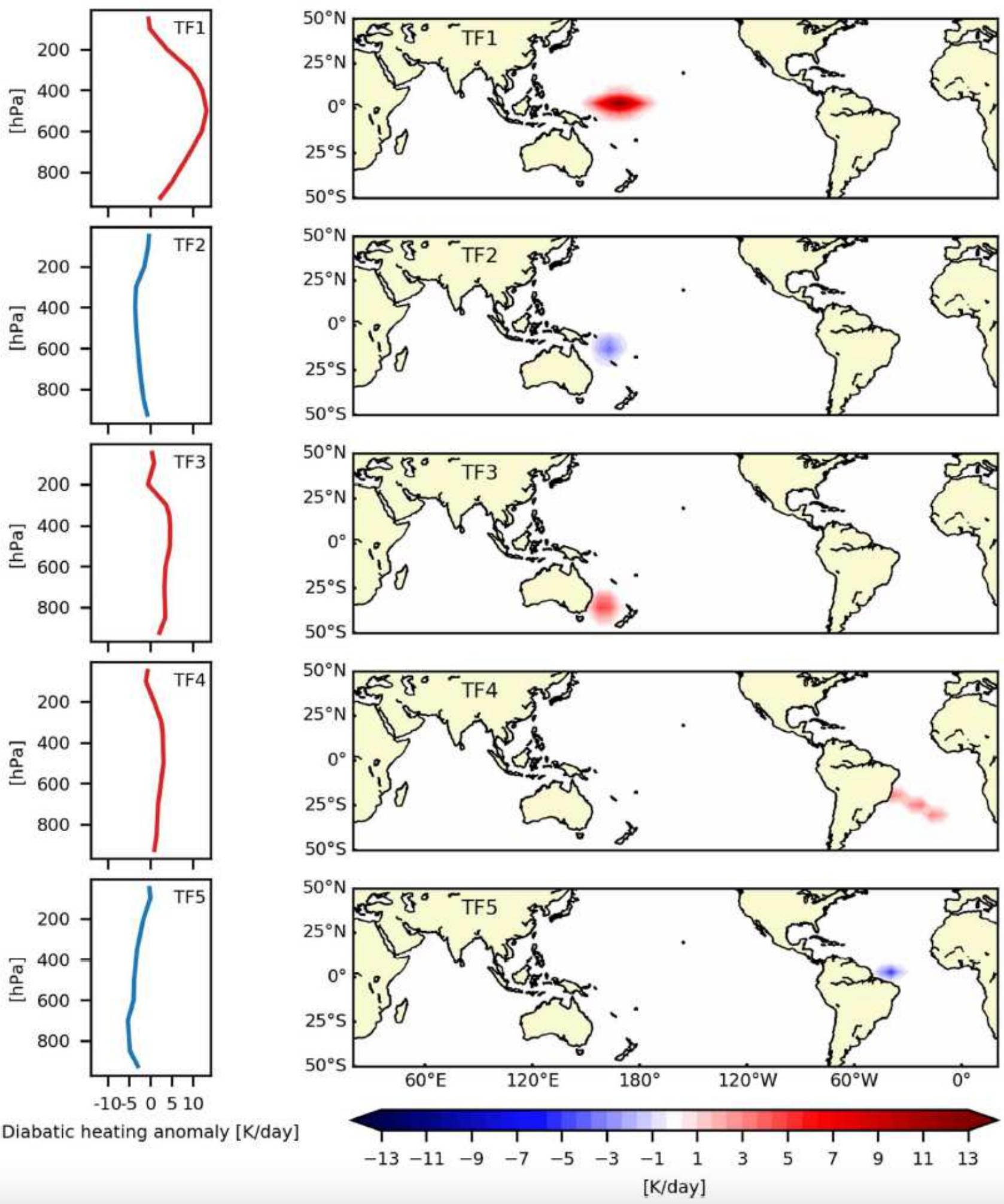

\section{Figure 8}

Vertical and horizontal distributions of the diabatic heating anomalies incorporated into the model's temperature tendency equation. TF stands for thermal forcing 
TF2 + TF3

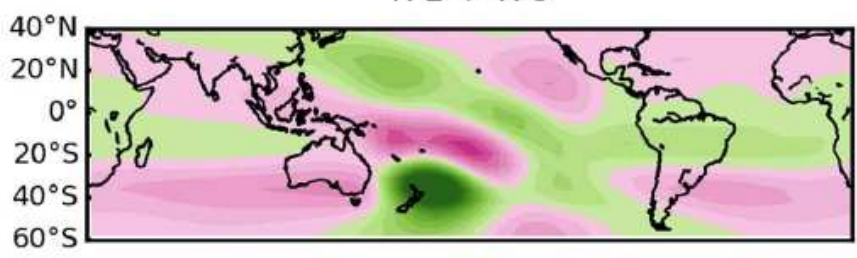

$\mathrm{TF} 2+\mathrm{TF} 3+\mathrm{TF} 4$

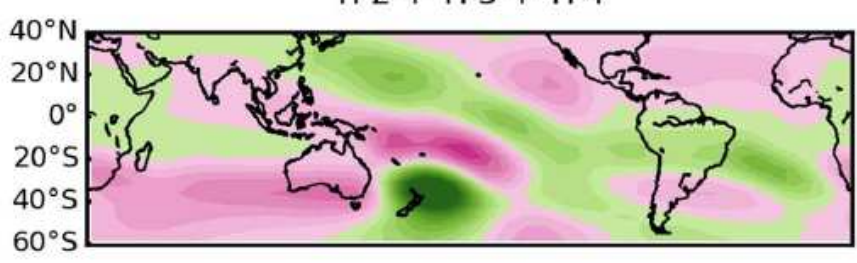

$\mathrm{TF} 1+\mathrm{TF} 2+\mathrm{TF} 3+\mathrm{TF} 4$

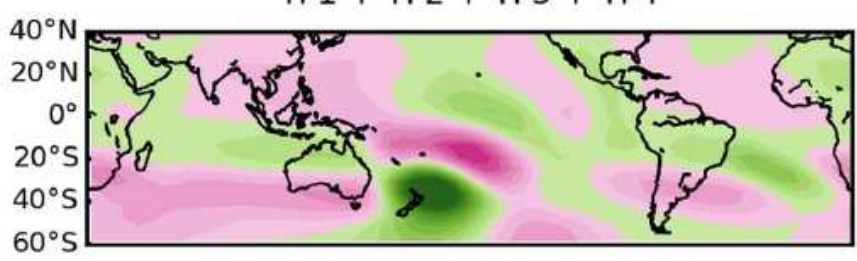

$\mathrm{TF} 1+\mathrm{TF} 2+\mathrm{TF} 3+\mathrm{TF} 4+\mathrm{TF} 5$

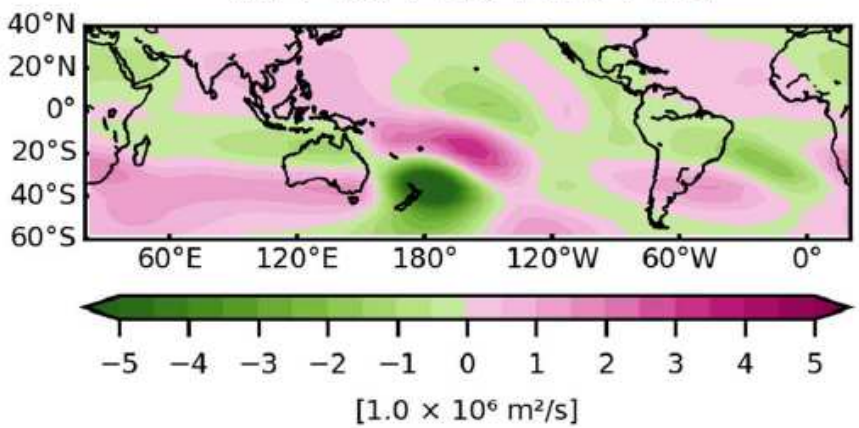

TF2 + TF3

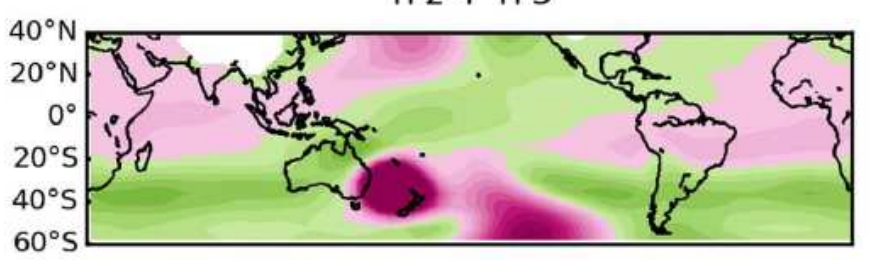

$\mathrm{TF} 2+\mathrm{TF} 3+\mathrm{TF} 4$

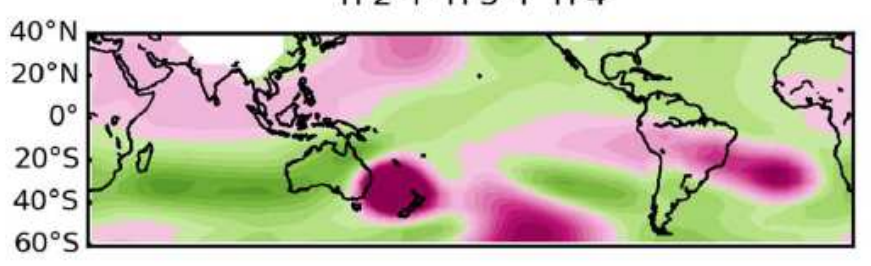

$\mathrm{TF} 1+\mathrm{TF} 2+\mathrm{TF} 3+\mathrm{TF} 4$

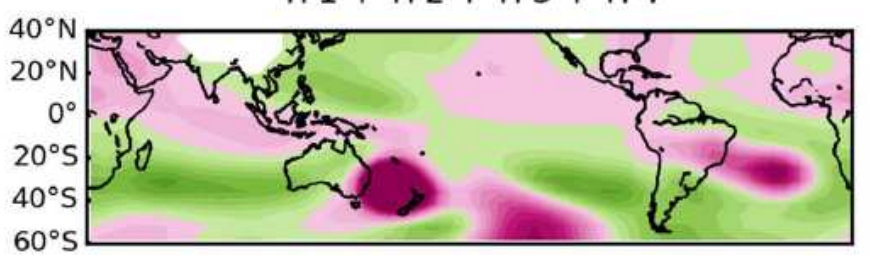

$\mathrm{TF} 1+\mathrm{TF} 2+\mathrm{TF} 3+\mathrm{TF} 4+\mathrm{TF} 5$

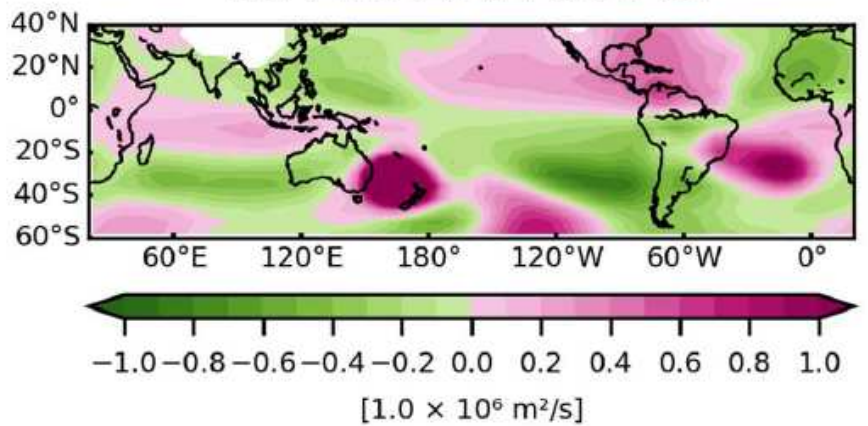

$\left[1.0 \times 10^{6} \mathrm{~m}^{2} / \mathrm{s}\right]$

Figure 9

Modelled $200-\mathrm{hPa}$ (left panels) and $850 \mathrm{hPa}$ (right panels) zonally asymmetric streamfunction (ZASTRF) results on the 15th day of simulation considering combinations among the thermal forcings (TFs) $1,2,3$, 4 , and 5 


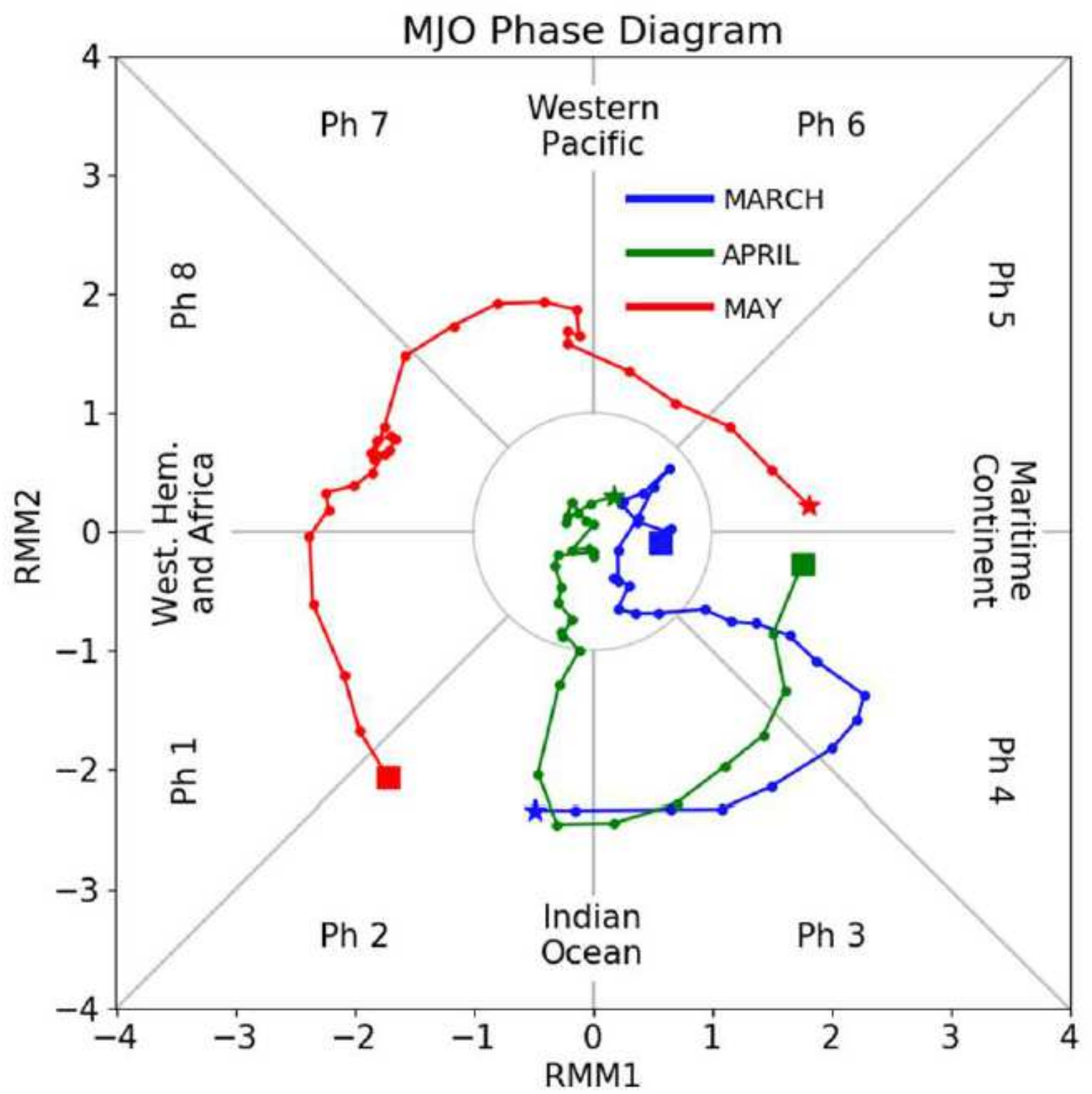

Figure 10

RMM diagram for March (blue), April (green), and May (red) 2019. Stars and squares represent the first and last days of the months, respectively. Full circles indicate the other days of the month, in ascending order, connected by straight lines. The central circle indicates an inactive MJO. Each region comprises the two MJO phases that are expected to enhance atmospheric convection over that region 


\section{Unfiltered}

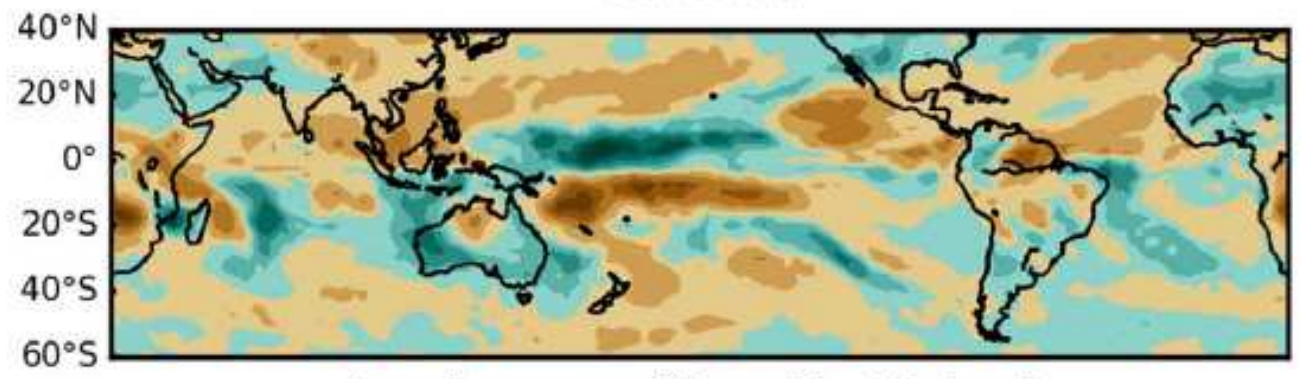

Low-frequency filtered (> 90 days)

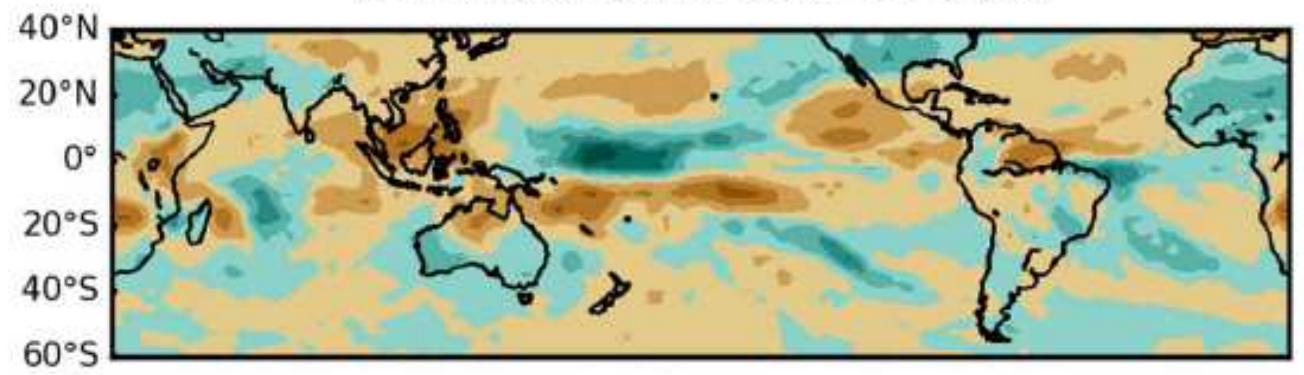

Sub-seasonally filtered (30-90 days)

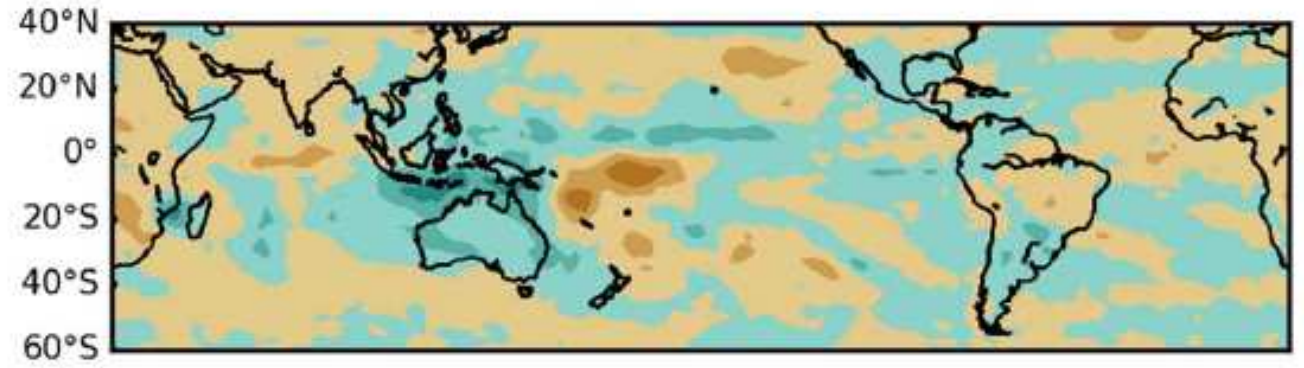

Sub-seasonally filtered (30-90 days) - 10 days

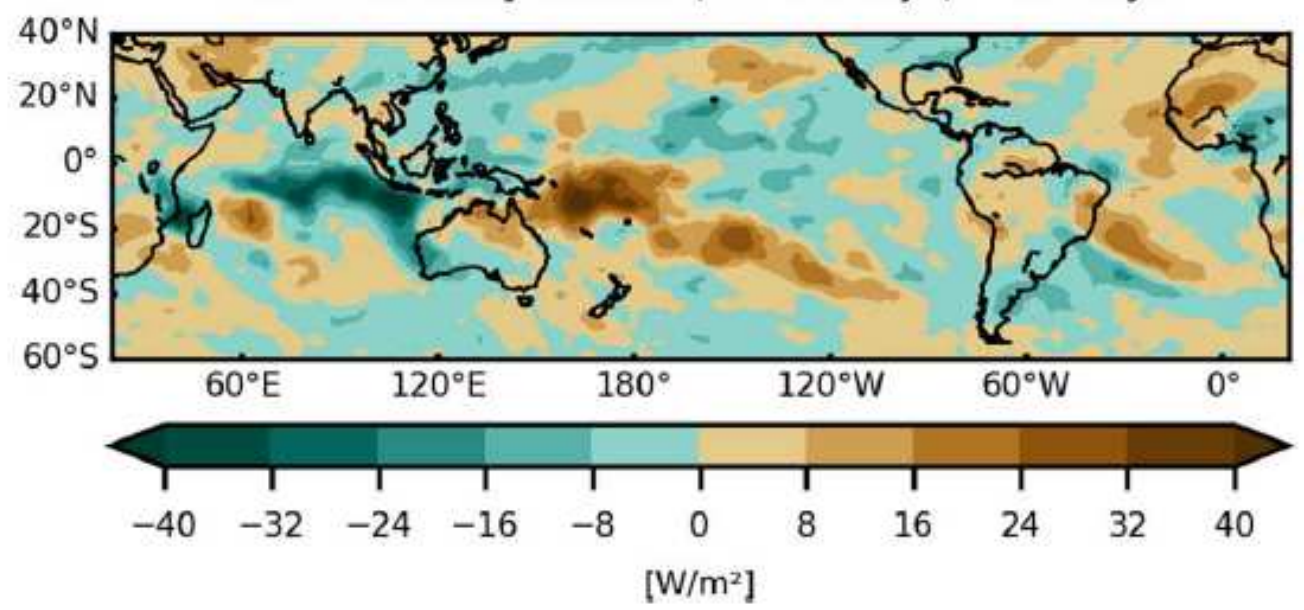

Figure 11

Mean outgoing longwave radiation (OLR) for March 2019: (upper panel) unfiltered; (upper-middle panel) low-frequency filtered (>90 days); (lower-middle panel) sub-seasonally filtered (30-90 days); and (lower panel) the first ten days of March 2019. Averages were calculated using daily OLR anomalies 